\title{
LA FALTA DE VALOR \\ DE LA JURISPRUDENCIA COMO CIENCIA
}

\section{Julius Hermann von KIRCHMANN}

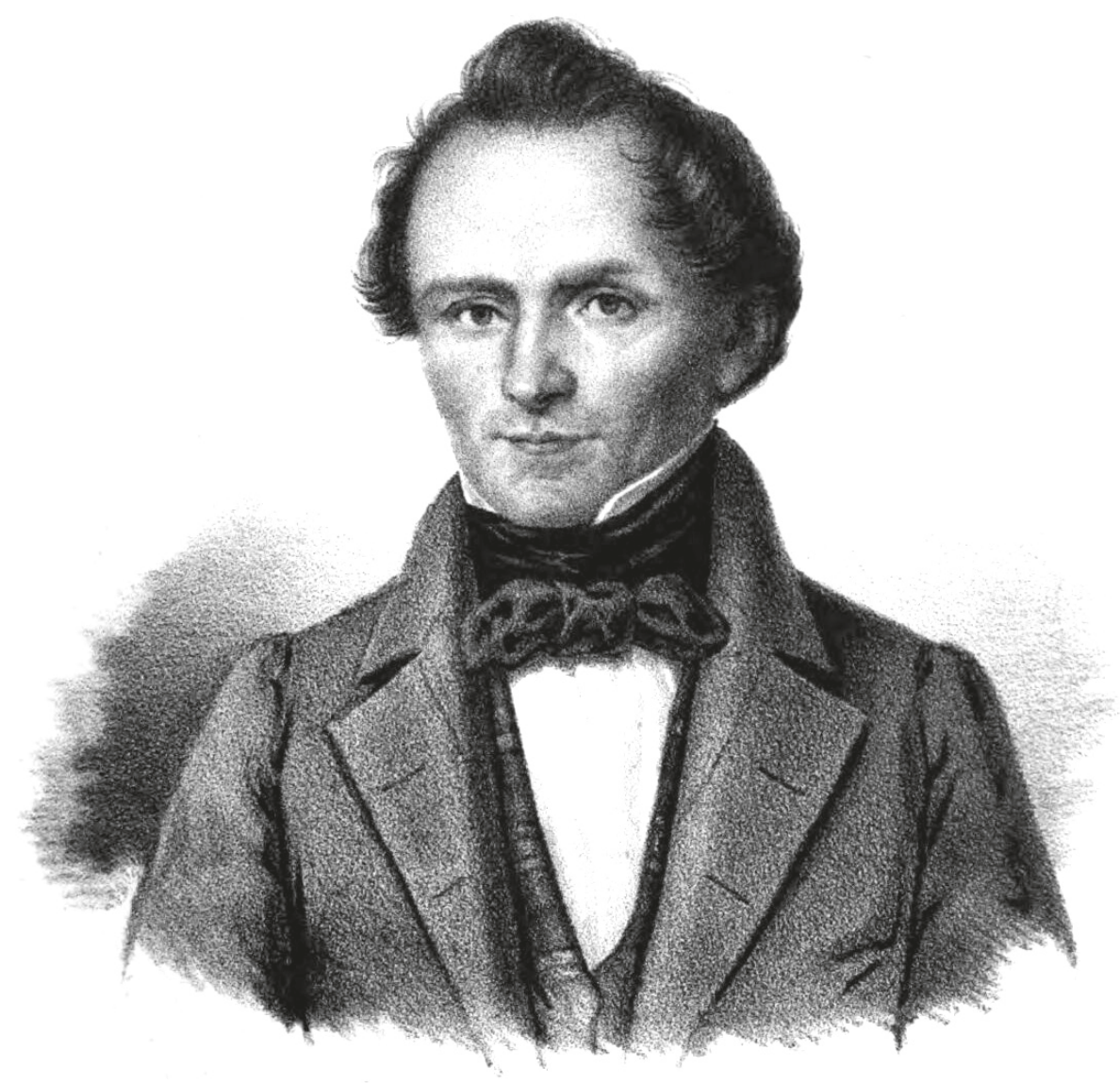



LA FALTA DE VALOR DE

LA JURISPRUDENCIA COMO CIENCIA 
The Figuerola Institute

Programme: Legal History

The Programme "Legal History" of the Figuerola Institute of Social Science History -a part of the Carlos III University of Madrid- is devoted to improve the overall knowledge on the history of law from different points of view -academically, culturally, socially, and institutionally- covering both ancient and modern eras. A number of experts from several countries have participated in the Programme, bringing in their specialized knowledge and dedication to the subject of their expertise.

To give a better visibility of its activities, the Programme has published in its Book Series a number of monographs on the different aspects of its academic discipline.

Publisher:

Carlos III University of Madrid

Book Series:

Legal History

Editorial Committee:

Manuel Ángel Bermejo Castrillo, Universidad Carlos III de Madrid

Catherine Fillon, Université Jean Moulin Lyon 3

Manuel Martínez Neira, Universidad Carlos III de Madrid

Carlos Petit, Universidad de Huelva

Cristina Vano, Università degli studi di Napoli Federico II

More information at www.uc3m.es/legal_history 
La falta de valor de la jurisprudencia como ciencia

Julius Hermann von Kirchmann

Traducción y presentación de

Manuel Alberto Navarro De las Heras

Universidad Carlos III de Madrid

ORCID ID: OOOO-0001-8929-9552

Manuel Martínez Neira

Universidad Carlos III de Madrid

ORCID ID: OOOO-OOO3-2572-4366

DYKINSON

2021 
Publicación financiada por el proyecto de investigación "Disciplinas académicas jurídicas. De la época liberal al régimen franquista” (PID2019109351GB-C32) del Ministerio de Ciencia e Innovación, España.

Historia del derecho, 97

ISSN: 2255-5137

(C) 2021 Manuel Alberto Navarro De las Heras

(C) 2021 Manuel Martínez Neira

Editorial Dykinson

c/ Meléndez Valdés, 61 - 28015 Madrid

Tlf. (+34) 915442846

E-mail: info@dykinson.com

http://www.dykinson.com

Preimpresión: TALLERONCE

ISBN: 978-84-1377-484-8

Versión electrónica disponible en e-Archivo

http://hdl.handle.net/10016/32336

\section{(c) (i) (8) $\Theta$ \\ BY NC ND}

Licencia Creative Commons Atribución-NoComercial-SinDerivadas 3.o España 
ÍNDICE

\author{
9 La maldición de Kirchmann \\ 13 Bibliografía \\ 14 Nota de edición \\ 15 La falta de valor de la jurisprudencia \\ como ciencia
}





\section{LA MALDICIÓN DE KIRCHMANN}

Recientemente, Marco Rossetti (del Tribunal de casación italiano) recordaba la maldición que Kirchmann echó a los juristas y que se ha convertido en proverbial: "tres palabras rectificadoras del legislador y bibliotecas enteras se convierten en papel mojado" . Frase afortunada que ha situado en la historia a su autor y al discurso en el que la pronunció. Y es que raramente una conferencia ha tenido un impacto tan duradero como esta ${ }^{2}$.

Julius Hermann von Kirchmann (Schafstädt 1802-Berlín 1884) fue un hombre polifacético. Se le recuerda como jurista ${ }^{3}$, político y filósofo $^{5}$. Aquí nos interesa lo primero, para contextualizar la conferencia que dictó en otoño de 1847 en una sociedad jurídica de Berlín con el título Die Werthlosigkeit der Jurisprudenz als Wissenschaft, es decir: La falta de valor de la jurisprudencia como ciencia, donde el término jurisprudencia tiene el significado clásico de

1 Marco Rossetti, "La maledizione di Kirchmann, ovvero che ne sarà del danno differenziale”, Questione Giustizia, 2019, online.

Las palabras de Kirchmann en la página 30 de esta edición.

2 Sobre ello llamó la atención Imre Zajtay en su reseña a la edición alemana de 1966: Revue internationale de droit comparé, 19/1 (1967), pp. 319-320.

Este impacto se manifiesta en las numerosas ediciones que la obra ha tenido en alemán y también en algunas traducciones. Véase ahora, la cuidada bibliografía (aunque contiene algunas omisiones, como la edición argentina de 1949 o la tercera edición de Truyol de 1983) disponible en: Rainer A. Bast (hrsg.), Julius Hermann von Kirchmann, pp. 66-67.

También se manifiesta en la atención que ha tenido su obra. Véase, por ejemplo, solo en castellano y recientemente: Enrique P. Haba, “Kirchmann sabía menos... iPero vio mejor! Vigencia de un antiguo diagnóstico, más algunas observaciones (que no son simpáticas) sobre la actual Teoría del Derecho”, Doxa 14 (1993), pp. 269-317; Mariano H. Novelli, “Las ideas de Kirchmann acerca de la ciencia jurídica. Consideraciones sobre epistemología y derecho", Revista del Centro de Investigaciones de Filosofía Jurídica y Filosofía Social, 29 (2006), pp. 103-109; Juan Carlos Fitta Quirino, "La jurisprudencia no es ciencia. A 125 años de la muerte de Julius Hermann von Kirchmann”, Argumentos, 23/64 (2010), online.

3 Hermann Klenner, "Kirchmann als Rechtstheoretiker", en Rainer A. Bast (hrsg.), Julius Hermann von Kirchmann, pp. 1-13.

4 Holger Scheerer, "Kirchmann als Politiker", en Rainer A. Bast (hrsg.), Julius Hermann von Kirchmann, pp. 15-33.

5 Rainer A. Bast, "Kirchmann Philosophie”, en Rainer A. Bast (hrsg.), Julius Hermann von Kirchmann, pp. 35-52. 
ciencia jurídica. Puede parecer una provocación, como lo admite el propio autor en distintos momentos del escrito, empezando por el primer párrafo del mismo, donde se defiende ante tal frivolidad ${ }^{6}$. Pero en todo caso se trataría de la provocación de un hombre de 45 años, con buena formación jurídica y con gran experiencia en la administración de justicia.

Sajón de nacimiento, las guerras napoleónicas y las cesiones territoriales lo terminaron situando en el Reino de Prusia, posterior germen del II Imperio Alemán. Realizó sus estudios jurídicos en las universidades de Leipzig y Halle. Tras graduarse en 1823, comenzó su carrera dentro de la administración de justicia del Reino de Prusia. La formación y el desarrollo intelectual del autor se sitúan, por tanto, en una época de profundos cambios en las tendencias filosóficas y las instituciones políticas de Europa. Tras la prolífica generación del Aufklärung, comienza un movimiento romántico y nacionalista como contestación a los acontecimientos históricos de principios de siglo.

La carrera judicial y como procurador del autor culminan, casi de forma coincidente, con la presente conferencia. En ningún caso puede entenderse una relación causal entre ambos sucesos. Fue la coincidencia temporal de su publicación con los sucesos de 1848 los que, entre otras cosas, lanzaron a Julius von Kirchmann hacia la representación política. Electo al Parlamento de Fráncfort en 1848, se integró en las facciones del ala izquierda del Zentrum. Tomó parte activa en la redacción de la Constitución de Fráncfort de 1849, interviniendo en múltiples cuestiones de especial interés, como el diseño del Estado, el reconocimiento de la soberanía popular y la organización interna de un territorio fraccionario y con autoridades propias.

Aunque finalmente la negativa regia al proyecto lo hizo sucumbir, Kirchmann se mantuvo hasta pocos años antes de su muerte como representante de las posturas liberales en la Cámara de Representantes del Reino de Prusia. Durante sus 28 años de carrera política no faltaron las polémicas y confrontaciones, tanto con autoridades prusianas como con colegas en la Cámara.

Julius von Kirchmann no puede considerarse, hasta la publicación de la presente obra, un teórico del derecho. Tan sólo esta breve obra y una adicional posterior, tanto más extensa como desconocida ${ }^{7}$, sitúan su persona como

6 Este carácter provocador ha sido señalado muchas veces, últimamente por Giorgio Resta, "Les luttes de clocher en droit comparé", MacGill Law Journal/Revue de droit de McGill, 62/4 (2017), pp. 1153-1199, en concreto 1176.

7 Die Grundbegriffe des Rechts und der Moral als Einleitung in das Studium rechtsphilosophischer Werke, Berlín 1869; $2^{\text {a }}$ ed. 1873. 
contribuidor al desarrollo del análisis de la teoría del derecho. Su carácter forjado como un auténtico práctico del derecho hasta la conferencia sobre "La falta de valor de la jurisprudencia como ciencia" es, muy posiblemente, la razón de la idea aquí planteada. Julius von Kirchmann combinó en su haber una vasta experiencia en la aplicación del derecho junto con una carrera en la academia, hecho atípico en los autores contemporáneos.

$$
* *
$$

Pasemos a analizar brevemente la conferencia. El título, dice Kirchmann, puede indicar dos cosas: que la ciencia jurídica carece de influencia; que no es ciencia. Y quiere mantener esa ambigüedad, pues "ambos sentidos muestran lo que pretendo expresar" (p. 19)

El autor parte de la antítesis entre objeto y ciencia. Desde esta perspectiva, explica cómo la jurisprudencia se ocupa de un objeto que existe de forma autónoma, al margen de la ciencia que lo cultiva. El objeto de la jurisprudencia es el derecho natural, en el sentido del derecho tal y como lo vive el pueblo, como se realiza en la esfera de cada individuo. Plantea así la distinción entre ese derecho natural y la ciencia jurídica. De hecho -dirá-, como demuestra el estudio de la historia, un pueblo puede vivir sin jurisprudencia pero no sin derecho.

Por otro lado, la jurisprudencia, como las demás ciencias, "tiene que comprender su objeto, encontrar sus leyes, crear para ello conceptos [...], resumir su conocimiento en un sistema simple" (p. 21). ¿Cómo ha logrado esto la jurisprudencia? Este es el problema al que se enfrenta el autor y su respuesta la conocemos. Y para resolverlo - para demostrar la falta de valor de la ciencia jurídica- propone una doble vía: comparar el objeto de la jurisprudencia con los de las otras ciencias (pp. 23 ss.); mostrar la fuerza destructiva de la ciencia jurídica sobre el derecho (pp. 35 ss.).

8 De ahí que podamos considerar desafortunado el título que dio Truyol a su traducción, pues (seguramente llevado por la fuerza retórica del mismo) traiciona la ambigüedad buscada por el autor al decantarse de entrada por uno de los dos significados. Alejándose además de la denominación de la obra en otras lenguas romances. Así, la referencia francesa: La futilité de la théorie du droit en tant que science (Imre Zajtay, cit.). O la traducción italiana: Della mancanza di valore della giurisprudenza come scienza: discorso, trad. y prefacio de Paolo Frezza, Pisa, Pacini Mariotti, 1942 (esta traducción se publicó de nuevo en Julius Hermann von Kirchmann/Erik Wolf, Il valore scientifico della giurisprudenza, Milán, Giuffrè, 1964). 
La primera vía conduce a observar algunas peculiaridades del derecho. En primer lugar su naturaleza mudable ${ }^{9}$. Ante un derecho en continuo cambio, que evoluciona incesantemente, la ciencia por un lado se opone a ese progreso; por otro, tiende a privilegiar el estudio histórico y no el del derecho actual, que es lo que importa. La segunda peculiaridad es que se trata de un objeto que es a la vez conocimiento y sentimiento. Esta naturaleza sentimental -por su carácter no objetivo- dificulta la ciencia. Por último, la tercera peculiaridad está constituida por la existencia de la ley positiva, esa forma híbrida de ser y conocer que se entromete entre el derecho y la ciencia, mortificando a ambos. La ley positiva hace que la ciencia se dedique a lo accidental y, así, ella misma se convierta en accidental: tres palabras del legislador...

La segunda vía le lleva a analizar cómo la ciencia "al querer entender su objeto [el derecho], lo aniquila”. Esta convierte el derecho en patrimonio exclusivo de una clase erudita, y como consecuencia de ello el pueblo se ve expropiado de su derecho: no se reconoce en el derecho oficial, desconfía de los abogados y de los jueces de carrera, se refiere a la administración de justicia como si fuera un juego de azar.

El resultado al que llega a través de estas dos vías es "devastador y angustioso” (p. 43). Pero siempre queda el consuelo de considerar su necesidad y la superioridad de la nación.

Wieacker sitúa a Kirchmann como representante del naturalismo social ${ }^{10}$. Es interesante su reflexión: casi todos los movimientos opuestos a la escuela histórica y al positivismo jurídico pueden reconducirse a esta protesta antiformalista contraria a la renuncia de la ciencia jurídica al contacto con la realidad social (protesta donde se incluye también al marxismo).

Aunque Kirchmann siga siendo conocido fundamentalmente por su maldición, quizá esta ulterior consideración -la necesidad de una ciencia jurídica en contacto con la realidad social- sirva para comprender mejor su mensaje y ayude a situarlo en el contexto de la cultura jurídica contemporánea.

9 Kiesow parte de Kirchmann para comparar ciencias naturales y ciencia del derecho, desde el punto de vista de la evolución del derecho. Véase, Rainer Maria Kiesow, L'unité du droit, París, EHESS, 2014, pp. 51 ss.

10 Franz Wieacker, Storia del diritto privato moderno, vol. 2, Milán 1980, p. 82. 


\section{BIBLIOGRAFÍA CITADA}

Rainer A. Bast (hrsg.), Julius Hermann von Kirchmann. 1802-1884. Jurist, Politiker, Philosoph, Hamburg 1993.

Juan Carlos Fitta Quirino, "La jurisprudencia no es ciencia. A 125 años de la muerte de Julius Hermann von Kirchmann", Argumentos, 23/64 (2010), online.

Enrique P. Haba, "Kirchmann sabía menos... iPero vio mejor! Vigencia de un antiguo diagnóstico, más algunas observaciones (que no son simpáticas) sobre la actual Teoría del Derecho", Doxa, 14 (1993), pp. 269-317.

Rainer Maria Kiesow, L'unité du droit, París, École des hautes études en sciences sociales, 2014.

Hermann Klenner, "Kirchmann als Rechtstheoretiker", en Rainer A. Bast (hrsg.), Julius Hermann von Kirchmann, pp. 1-13.

Mariano H. Novelli, "Las ideas de Kirchmann acerca de la ciencia jurídica. Consideraciones sobre epistemología y derecho", Revista del Centro de Investigaciones de Filosofía Jurídica y Filosofía Social, 29 (2006), pp. 103-109.

Giorgio Resta, "Les luttes de clocher en droit comparé", MacGill Law Journal/ Revue de droit de McGill, 62/4 (2017), pp. 1153-1199.

Holger Scheerer, “Kirchmann als Politiker”, en Rainer A. Bast (hrsg.), Julius Hermann von Kirchmann, pp. 15-33.

Franz Wieacker, Storia del diritto privato moderno (1967), vol. 2, Milán, Giuffrè, 1980.

Imre Zajtay, "Bibliographie" (reseña de la edición alemana de 1966), Revue internationale de droit comparé, 19/1 (1967), pp. 319-320. 


\section{NOTA DE EDICIÓN}

La primera traducción de esta obra al castellano fue hecha por Werner Goldschmidt, miembro del Instituto argentino de filosofía jurídica y social, y publicada junto a otras obras en un libro titulado La ciencia del derecho en $1949^{11}$.

El mismo año apareció la traducción de Antonio Truyol Serra, quien propuso un título original: La jurisprudencia no es ciencia ${ }^{12}$, con el que traicionaba la ambigüedad buscada por Kirchmann (p. 19). Esta traducción tuvo una segunda edición en 1961, con una "nota adicional". Y una tercera en 1983, mera reimpresión.

Ediciones Olejnik ofreció en 2018 una edición algo desconcertante. Como título propone el de Truyol y como subtítulo el de Goldschmidt, cuya traducción es la que reproduce, sin reconocer la autoría. A esto añade estudios previos de Haba y Novelli ${ }^{13}$.

Aquí proponemos una nueva traducción basada fielmente en la primera edición de $1848^{14}$, añadiendo alguna nota al pie.

11 Julio Germán von Kirchmann, "El carácter a-científico de la llamada ciencia del derecho", en Savigny, Kirchmann, Zitelmann, Kantorowicz, La ciencia del derecho, Buenos Aires, Losada, 1949, pp. 247-286.

12 J. H. von Kirchmann, La jurisprudencia no es ciencia, traducción y escrito preliminar de Antonio Truyol Serra, Madrid, Instituto de Estudios Políticos, 1949 (= vol. 1 de la Colección Civitas); 2. ${ }^{\mathrm{a}}$ ed., 1961; 3. ${ }^{\mathrm{a}}$ ed., 1983.

13 Julius Hermann von Kirchmann, La jurisprudencia no es ciencia. El carácter acientífico de la llamada ciencia del derecho, estudio liminar de Enrique P. Haba, presentación de Mariano H. Novelli, Santiago de Chile, Ediciones Olejnik, 2018.

14 Die Werthlosigkeit der Jurisprudenz als Wissenschaft, Berlín, Springer, 1848. En 1848 tuvo tres ediciones, prácticamente idénticas. La primera con una caja menor, por lo que tenía más páginas. 


\section{La falta de valor}

de

la jurisprudencia como ciencia.

Conferencia,

pronunciada

en la Sociedad Jurídica de Berlín,

por

el Procurador von Kirchmann.

Berlín, 1848.

Editorial de Julius Springer,

Breite Straße n. ${ }^{0} 20$. 



\section{Prólogo}

Publico las siguientes páginas por deseo de varias personas conocidas. Además, dicha publicación constituye el mejor medio para evitar equívocos y malas interpretaciones, inevitables cuando en una conferencia se exponen pensamientos poco comunes.

El lector perdonará el estilo del escrito. Un discurso oral y dictado en gran parte sin base escrita, lo hace necesario e inevitable. 

$\mathrm{E}_{1}$ título de mi conferencia de hoy puede hacer pensar fácilmente que únicamente he buscado la polémica, sin preocuparme de la verdad que subyace al asunto.

Debo comenzar defendiéndome de tal suposición. Tal labor puede ser gratificante y entretenida si se hace con la debida habilidad; no obstante, la consideración que le debo al carácter de esta Sociedad y a la seriedad de sus miembros me lleva a evitar tratar de esa forma mi tema.

Por lo tanto, debo advertir de antemano que todo lo que me permitiré decir es mi auténtica convicción y que mi objetivo no es otro que la verdad, la haya o no encontrado.

El tema que he planteado padece de cierta ambigüedad. "La falta de valor de la jurisprudencia ${ }^{1}$ como ciencia” puede llevar a considerar que la jurisprudencia, aun siendo ciencia, carece de influencia sobre la realidad y la vida de los pueblos, como por el contrario se espera y corresponde a toda ciencia. Pero también puede significar que la jurisprudencia es teoréticamente inútil como ciencia, que no es ciencia con arreglo al auténtico concepto de la misma.

No quiero rechazar esta ambigüedad, que involuntariamente se ha introducido en mi tema: ambos sentidos muestran lo que pretendo expresar.

Bien es verdad que semejantes afirmaciones no son corrientes. La santidad y la nobleza de la jurisprudencia aún permanecen inquebrantables, universalmente reconocidas; $\mathrm{y}$, sin embargo, la experiencia diaria contiene algunos fenómenos que bien podrían suscitar múltiples dudas sobre esta convicción. ¿Cuántos juristas en ejercicio experimentan a veces la profunda sensación de vacío e inadecuación de su profesión? ¿Qué otra rama de la ciencia tiene, junto a cosas buenas, tal mezcolanza de libros sin sentido y de mal gusto como la jurídica? La sacrosanta justicia sigue siendo para el pueblo, hasta el día

1 El término jurisprudencia siempre se utiliza como sinónimo de ciencia del derecho. Todas las notas son de la edición. 
de hoy, objeto de burla; y las mismas personas cultas, aunque lleven razón, temen caer en sus manos, tratando en vano de orientarse en medio de sus formalidades y procedimientos. iQué multitud de leyes y, sin embargo, cuántas lagunas! iQué ejército de oficiales y, sin embargo, qué lentitud en la administración de justicia! iQué exceso de estudios y erudición y, sin embargo, qué fluctuaciones, qué incertidumbre en la teoría y en la práctica! iUn Estado que hace de la realización del derecho su tarea más elevada y, sin embargo, hace pagar con elevadas sumas la aplicación del derecho al caso concreto!

$\mathrm{El}$ acostumbramiento hace que incluso los mejores juristas miren tales fenómenos con indiferencia, y si el profano se atreve a abrir la boca, se le rechaza cortésmente por no entender sobre la materia. Pero estos fenómenos son demasiado frecuentes para no ser considerados como señales de incongruencias más profundas y, a la vez, son lo suficientemente importantes como para que cualquier intento de encontrar las razones de estos fenómenos pueda contar con el interés de los honrados oyentes.

La jurisprudencia, como cualquier otra ciencia, se ocupa de un objeto que existe de forma autónoma, libre e independiente en sí mismo, sin preocuparse de la existencia de la ciencia misma o del alcance de su entendimiento. Este objeto es el derecho, tal y como vive en el pueblo, como se realiza en la esfera de cada individuo: puede denominarse derecho natural ${ }^{2}$. Esta misma situación se da en todas las demás ciencias. La naturaleza es objeto de las ciencias naturales: la flor florece y el animal vive, independientemente de que la fisiología conozca su naturaleza o sus fuerzas. El alma es objeto de la psicología; la mente, en su mera función de pensar, es el objeto de la lógica. La gente sentía y pensaba de la misma manera antes y después del desarrollo de estas ciencias. Tampoco las matemáticas se ocupan de objetos ficticios. Las relaciones de espacio y de números son abstracciones, pero son siempre abstracciones de la realidad: el teorema de Pitágoras existía en su verdad antes de que Pitágoras lo descubriera. Incluso la filosofía tiene su objeto real, absoluto y eterno, a través del cual la ciencia debe abrirse paso.

De hecho, la filosofía moderna ha intentado desdibujar esta antítesis entre objeto y ciencia, pero aquí es posible ignorar convenientemente ese intento.

Esa supuesta identidad del ser y del conocimiento sólo fue afirmada por aquellos grandes pensadores en el cúlmine de su método, aunque posteriormente, esa oposición reaparece también en ellos. El que la naturaleza no se la

2 El concepto de derecho natural es siempre este: el derecho tal y como vive en el pueblo, como se realiza en la esfera de cada individuo. 
llame "naturaleza", sino "idea en la forma de la alteridad", no suprime dicha antítesis; lo único que con ello se hace es trasladarla del sujeto a su atributo.

El objeto de la jurisprudencia es por tanto el derecho; y, visto más de cerca, son las instituciones del matrimonio, la familia, la propiedad, los contratos, la herencia, las diferencias entre clases, la relación del gobierno con el pueblo o de las naciones entre ellas. Esta independencia del derecho, en relación a la ciencia, es un principio de gran importancia. A menudo ha sido cuestionado o se ha tratado de restringir, pero para demostrar su corrección más allá de toda duda bastan simples consideraciones. Un pueblo puede existir sin jurisprudencia, pero nunca sin derecho; de hecho, el derecho debe haber alcanzado cierto nivel de desarrollo antes de plantearse la ciencia jurídica. La historia corrobora esto mismo. En Grecia, la vida pública y familiar ya había progresado de modo importante y, sin embargo, la jurisprudencia apenas se había incoado. Lo mismo ocurrió con los romanos hasta la caída de la República, y también con los pueblos germánicos y románicos de la Edad Media hasta los tiempos de los glosadores.

En comparación con el objeto de otras ciencias, el derecho contiene una diferencia que tal vez suscite dudas aquí: nos referimos al saber que es inherente al derecho también en cuanto objeto de la ciencia.

Esta diferencia existe realmente. Un pueblo tiene conocimiento de su derecho incluso sin jurisprudencia, pero ese conocimiento no puede ser ciencia. Este, que descansa en las recónditas regiones del sentimiento, de la intuición natural, es sólo un conocimiento del derecho en el caso concreto. Es cierto que también manifiesta principios abstractos en los proverbios jurídicos, pero tales brocardos lejos de revestir sentido científico pueden aplicarse o no: lo determinante es la particularidad del caso dado y no aquella máxima. La lingüística nos ofrece una excelente analogía: su objeto también contiene el elemento del conocimiento. El individuo al hablar sabe cómo usar los casos y tiempos verbales con total precisión y, sin embargo, la gramática, la ciencia del lenguaje, con frecuencia apenas si la conoce por su nombre.

La tarea de la jurisprudencia es, por tanto, la misma que la de todas las demás ciencias: tiene que comprender su objeto, encontrar sus leyes, crear para ello conceptos, reconocer la relación y la conexión de las diversas instituciones y, finalmente, resumir su conocimiento en un sistema simple. Mi tema se reduce así a la pregunta: ¿cómo resolvió la jurisprudencia este asunto? En concreto, ¿cómo lo ha hecho en comparación con otras ciencias? ¿Está a la vanguardia o, por el contrario, se ha quedado atrás? 
Cabría pensar que el saber, elemento que como acabamos de ver es inherente a su objeto, debería haber dado a la jurisprudencia una ventaja esencial sobre las otras ciencias; sin embargo, la historia enseña justo lo contrario. Entre los griegos, todas las demás ciencias ya estaban muy avanzadas cuando la jurisprudencia, con la excepción del derecho público, estaba por cultivar. Los juristas romanos de la era imperial recuperaron el tiempo perdido en lo que atañe al derecho penal y privado, y gracias a ello la ciencia jurídica brilló sobre todas las demás. En la edad media, que pudo contar con estos trabajos previos, se mantuvo durante mucho tiempo esta relación de superioridad. Pero a partir de la época de Bacon se produjo un cambio total. El principio de observación -la subordinación de la especulación a la experiencia-, al que en el fondo debe también su valor la jurisprudencia de los clásicos romanos, fue aceptado por todas las ciencias y los frutos de este nuevo método pronto rozaron lo prodigioso. Los descubrimientos se sucedieron rápidamente. Si con anterioridad, lo que se creía firmemente en un siglo, basándose en ilusas especulaciones, se veía arrumbado en el siguiente, por otras especulaciones de no menor calibre, ahora, en cambio, se contaba con firmes cimientos. Los trabajos y descubrimientos de un siglo sirvieron de base sólida para continuar la construcción en el siguiente, en el que se alcanzaban alturas más asombrosas si cabe. La jurisprudencia, en cambio, se quedó estancada desde la época de Bacon; sus reglas y conceptos no han mejorado desde entonces. Las controversias no han disminuido, sino aumentado. Incluso cuando la más ardua investigación cree haber logrado finalmente un resultado cierto e inquebrantable, apenas pasa una década y la disputa comienza de nuevo. Los escritos de [Jacques] Cujas, [Hugues] Doneau, [François] Hotman y [François] Douaren todavía se consideran ejemplares y el presente no ha producido nada mejor. Este hecho es reconocido por las más elevadas lumbreras científicas.

Con estas consideraciones externas no pretendo en ningún caso liquidar el asunto y afirmar que mi tarea está resuelta. El argumento central de mi tema requeriría establecer la definición de ciencia en general y relacionar con ella los logros de la jurisprudencia. Sin embargo, tal método comporta grandes dificultades y durante el tiempo limitado de mi conferencia resulta completamente impracticable. Además, el resultado obtenido se quedaría siempre en la superficie, mientras que las razones profundas de la diferencia permanecerían ocultas. Por ello quiero intentarlo de otra forma, porque si mi afirmación acerca del carácter acientífico de la jurisprudencia es cierta, está claro en primer lugar que la culpa no puede ser de las personas, de los cultiva- 
dores de la ciencia. Hay ejemplos en los que, para ciertos períodos de tiempo, el retraso de una ciencia en particular puede achacarse a sus cultivadores y estudiosos de entonces. Pero afirmar lo mismo para todos los milenios en los que en general ha existido la ciencia supone algo imposible y contradice la naturaleza de la mente humana, que es y sigue siendo igualmente vigorosa, independientemente del objeto al que se destine. Asumiendo, por tanto, que la jurisprudencia va realmente por detrás de las otras ciencias, la razón sólo puede estar en su propia materia, en secretas fuerzas maliciosas que son inherentes al propio objeto de estudio y entorpecen los esfuerzos del espíritu humano en este ámbito. El camino más correcto para examinar mi argumento será entonces comenzar comparando el objeto de la jurisprudencia con los de las otras disciplinas. Esta forma de tratar el tema, si resulta exitosa, ofrece la doble ventaja de comprobar la proposición en sí y de comprender las razones de la misma.

Ahora bien, al aplicar este método comparativo aparecen varias características que son propias del derecho y no se encuentran en el objeto de estudio de otras ciencias.

La primera peculiaridad que surge es la variabilidad del derecho natural como objeto de la jurisprudencia. El sol, la luna y las estrellas brillan hoy como hace miles de años; la rosa florece hoy como en el Edén; pero desde entonces el derecho ha cambiado. El matrimonio, la familia, el Estado y la propiedad se han desarrollado de la forma más diversas. El nombre más conocido para esta variabilidad de la materia es el desarrollo progresivo de las diversas instituciones jurídicas. Es costumbre considerar esta evolución como una ventaja; de hecho, incluso se ha llegado a dar sustantividad a este movimiento en sí mismo considerado, sin tener en cuenta su contenido o dirección. Tales afirmaciones son, cuanto menos, sorprendentes. No cabe duda de que la humanidad tenía ventajas indecibles por estar dotada desde el principio del mejor organismo posible, pero ¿̇no habría sido mucho más feliz si le hubieran adjudicado en el acto las instituciones legales más excelentes para el estado de su desarrollo? ¿Cómo puede ser una ventaja y una dicha que los pueblos tuvieran que luchar durante siglos con fatiga y dolores para obtener los bienes esperados? Sin embargo, estas preocupaciones no tienen cabida aquí. Nos basta con que haya progreso, ya sea una ventaja o un defecto. Aquí la única cuestión es saber qué efectos tiene esta mutabilidad del objeto en la ciencia. La respuesta a esta pregunta no puede ponerse en duda: el efecto es extremadamente perjudicial. Está en la naturaleza de toda ciencia que su 
verdad puede madurar sólo lentamente. Debe sortear errores de todo tipo, y sus leyes son sólo el resultado de siglos de esfuerzos colectivos de sus cultivadores. Para otras ciencias no hay nada malo en esta lenta progresión: la tierra sigue girando alrededor del sol hoy como hace mil años, los árboles crecen y los animales viven como en la época de Plinio. Aunque las leyes y fuerzas de su naturaleza sólo se hayan descubierto tras muchos esfuerzos, siguen siendo tan verdaderas en el presente como lo fueron en el pasado y lo seguirán siendo en el futuro. Esto choca radicalmente con el derecho. Cuando, tras largos años de esfuerzo, este último encuentra al fin el verdadero concepto, la ley de una institución, ya hace tiempo que la realidad se ha transformado. La ciencia siempre llega tarde, va por detrás de los cambios, nunca puede alcanzar al presente. Es como el viajero del desierto: por la mañana divisa a gran distancia los jardines en flor, los lagos ondulantes y, aun caminando todo el día, al anochecer siguen estando lejísimo. Se han hecho muchos esfuerzos para mejorar desde la época de Goethe, pero la burla de su Mefistófeles sigue siendo cierta a día de hoy. El Estado griego pudo entenderse cuando ya había perecido. La ciencia de las instituciones del derecho romano se llegó a completar cuando el ius gentium ya las había suplantado. El espíritu y la excelencia de la Constitución Imperial alemana se pudieron reconocer cuando Napoleón había borrado sus últimos vestigios. Este es el primer mal fundamental que padece nuestra ciencia, del que emanan múltiples consecuencias que la obstaculizan.

La primera de ellas es que la jurisprudencia tiende en general y de manera hostil a oponerse al progreso del derecho. Es más cómodo quedarse en una casa antigua, bien conocida y amueblada, que cambiar cada año y tener que instalarse y organizarse de nuevo. Pero incluso si la ciencia cede al progreso, aún conserva una tendencia predominante a encerrar las instituciones del presente en las viejas categorías de instituciones fenecidas. Ya los juristas romanos proporcionan ejemplos de esta tendencia.

Sus actiones utiles, sus quasi-delicta, quasi-contractus, quasi-possessio, su modelación de las instituciones libres de la etapa posterior, con base al patrón de los primeros tiempos, son claros ejemplos de esto.

Los juristas alemanes lo han hecho aún peor. El matrimonio y la patria potestad alemanes, las servidumbres alemanas y los estamentos fueron encerrados violentamente en conceptos del derecho romano con los que tenían poco más en común que el nombre; y donde el objeto se resistía demasiado a este procedimiento, la falta de libre concepción científica del mismo, obligó a aña- 
dirlo como usus modernus en las Instituciones romanas. Este procedimiento de los juristas alemanes es ahora considerado generalmente como un error; pero un error en el que han incurrido todos durante siglos, y que muestra que la inducción al mismo debe tener su base en la propia materia.

El mismo procedimiento sigue siendo utilizado hoy como modelo por los juristas latinos. Es sorprendente; como si el método más correcto no fuera, tanto para el derecho como en general, el análisis libre de los nuevos fenómenos, directamente, sin ideas preconcebidas, y dejar que de ellos emerjan los nuevos conceptos y leyes. Pues no toda institución jurídica, por haber surgido tras otra, procede de ella. El derecho privado en los primeros tiempos del Estado romano fue evidentemente producto del peor despotismo que la nobleza y los sacerdotes ejercieron sobre el pueblo. Formas y fórmulas rígidas inhibieron el tráfico y la persecución del derecho. El pueblo ignoraba incluso los días en que se concedía esto último. Todo el desarrollo del derecho privado en los tiempos de la República y el Imperio no es más que la progresiva liberación de estas trabas dentro del derecho. En oposición a esta corriente, los juristas romanos se aferraron a las viejas instituciones tiránicas con obstinada pedantería y las establecieron como forma principal, también para las instituciones del período posterior. De ahí esa dicotomía que atraviesa todo el sistema del derecho romano, ese repentino contraste entre las formas rígidas y la libre movilidad, el rigor literal y una equidad sin límites.

Este peligro que surge para la ciencia de la peculiaridad de su objeto, la ha inducido a menudo a entregarse con orgullo al derecho del pasado, relegando por completo el del presente a la despreciada labor de los juristas prácticos. Es demasiado tentador cultivar un campo al que las masas no tienen acceso, donde el brillo de la erudición adquiere su máxima intensidad, donde uno está seguro de que incluso los resultados más absurdos no pueden ser refutados por el sentido común. La escuela histórica proporciona suficiente evidencia de esto; sus maestros apenas han sabido escoger una vía intermedia.

En cualquier caso, debido a la mutabilidad de su objeto de estudio, la jurisprudencia está cargada con un lastre enorme: el estudio del pasado. El presente está justificado por sí solo. El pasado está muerto; sólo es valioso cuando es el medio para comprender y dominar el presente. Si la naturaleza de un objeto exige este entretenimiento, semejante a unos lentes mal graduados, entonces la ciencia debe resignarse, pero no es para festejarlo. Cuánto mejor sería si la jurisprudencia, como las ciencias naturales, pudiera abordar su 
objeto directamente. Este lastre de formaciones pasadas absorbe gran parte de las mejores fuerzas. El mal es tanto mayor porque las fuentes del derecho pasado son escasas y defectuosas. Lo que la diligencia y la intuición de siglos han reunido, puede derrumbarse de arriba abajo en cualquier momento por un simple pergamino antiguo recién encontrado. Sólo la lingüística se encuentra en una situación similar; su objeto también tiene un desarrollo progresivo, pero es decididamente mejor que la jurisprudencia porque el pasado de su objeto se conserva y se puede acceder en enorme proporción mediante los documentos y libros antiguos.

Si continuamos con la comparación, vemos una nueva peculiaridad del objeto de la jurisprudencia: el hecho de que el derecho no solo es conocimiento sino también sentimiento, su objeto no sólo se encuentra en la cabeza, sino también en el corazón. Los objetos de otras ciencias están exentos de este añadido. Si la luz es un movimiento ondulatorio del éter o el movimiento lineal de finos corpúsculos, si la razón y el entendimiento son uno o diferentes; si las ecuaciones algebraicas de cuarto grado pueden resolverse directamente o no, todas estas son preguntas interesantes, pero el sentimiento nunca se decide de antemano. Una u otra respuesta son igualmente bienvenidas; sólo se requiere la verdad. En el derecho, en cambio, iqué fanatismo, qué pasiones, qué facciones se mezclan con la búsqueda de la verdad! Todas las cuestiones del derecho público están impregnadas de sentimiento. La constitución o su ausencia, libertad o censura de la prensa, dos cámaras o una, si los judíos se pueden emancipar, si se mantiene o no la pena corporal; con sólo mencionar estas cuestiones, cada uno expresa su argumento. Asimismo en el derecho privado: si se permite el matrimonio entre cristianos y judíos, qué causas de divorcio deben admitirse, si deben existir o no los mayorazgos, la redención del derecho de caza... aquí y en casi todas las partes del derecho el sentimiento ya ha dado una respuesta antes incluso de que haya comenzado la investigación científica.

Esta peculiaridad del derecho no debe presentarse en modo alguno como un defecto. Al contrario, precisamente aquí es donde puede estar su mayor valor. Pero la cuestión de mi investigación es sólo si esto plantea un alivio o una dificultad para la ciencia del derecho. Y aquí es evidente que esto únicamente puede dificultar el trabajo de la ciencia. El sentimiento no es nunca y en ninguna parte un criterio de verdad. Es producto de la educación, del hábito, de la ocupación, del temperamento, es decir, del azar. Lo que escandaliza a un pueblo es celebrado por otro. Por tanto, para que la búsqueda de la 
verdad no vaya por mal camino, la primera condición es que se libere de este apresurado acompañante; y sin embargo casi nadie puede hacerlo en la investigación jurídica. La voluntad más fuerte no puede escapar por completo de las poderosas influencias de la educación y el hábito. Los resultados de esto están en todas partes. Todas las grandes cuestiones del día se han convertido en cuestiones de partido, mientras la verdad espera en vano a un investigador sin prejuicios. Los maestros de la ciencia, o no abordan la cuestión en absoluto, o si lo hacen, también ellos se han unido ya a una facción. Incluso si se encontrara la verdad, la pasión no dejaría que su voz penetre. Por lo tanto, es menester en el derecho que el tiempo con su poder tranquilizador pase por los problemas antes de que la ciencia pueda actuar y encontrar libremente la verdad. Aunque esto suele llegar demasiado tarde.

Qué brecha se muestra entre la jurisprudencia y las ciencias naturales; qué armonía, qué pacífico engranaje rige en estas últimas. Lo que uno descubre, lo recibe otro agradecido; todos trabajan juntos. Si una pasión se agita, es sólo la de la vanidad, que no se basa en la materia y, por tanto, pronto desaparece.

Un elemento característico que incumbe aquí, la censura, tiene su base natural sólo en esta conexión entre derecho y sentimiento. Sólo de esta manera la censura sobrevive a toda evidencia científica que la sorprende. El ataque contra la vieja y querida costumbre, contra la ley que se considera sagrada, subleva el corazón. Qué natural que el poder proteja su parecer con armas externas. La ciencia del derecho se ve así arrojada también a nuevos grilletes. Las ciencias naturales, y todas las demás ciencias, han conservado el hermoso privilegio de protegerse a sí mismas. Es cierto que se dice que también debe haber libertad de investigación científica para el derecho, solo que su resultado no debe propagarse al pueblo. Sin embargo, esto es como decirle a un maestro constructor: "puede dibujar y proyectar sus casas, mas no construirlas".

La comparación de las materias de las ciencias entre sí conduce a otra peculiaridad del derecho, cuyas consecuencias superan con creces las discutidas hasta ahora. Es la figura de la ley positiva, forma híbrida de ser y conocer que se entromete entre el derecho y la ciencia, y alcanza a ambos con sus perniciosos efectos.

Todas las ciencias tienen leyes y las leyes son su objetivo final. Todas las ciencias en todo momento tienen leyes falsas y verdaderas, pero su falsedad no influye sobre su materia. La tierra siguió girando alrededor del sol, a pesar de que Ptolomeo estableció lo contrario como una ley; el alma permaneció 
simple, a pesar de que Wolf y Kant la dividieron en innumerables potencias; el grano obtenía su principal alimento del aire y no del humus, a pesar de que hasta [Justus von] Liebig se dijera lo contrario como ley en economía.

Con las leyes positivas del derecho es diferente. Respaldadas por la fuerza y por sanciones, sean verdaderas o falsas, se imponen sobre su objeto. El derecho natural debe renunciar a su verdad y someterse a ellas. Mientras que en todos los demás campos el conocimiento deja incólume al ser y con reverencia cede ante él, en el derecho se impone lo contrario gracias a la ley positiva. El conocimiento, incluso incorrecto y defectuoso, vence al ser.

No se debe negar el tránsito necesario del derecho natural a la ley positiva. La cultura superior, la división del trabajo, el enredo de circunstancias, la necesidad de estabilidad y certeza, han llevado a todos los pueblos a las leyes positivas. No todo lo que surge de forma natural y necesaria es, por tanto, un beneficio. La humanidad en su devenir puede tomar caminos equivocados y, entonces, un cambio de rumbo puede ser aconsejable y factible.

Las desventajas de la ley positiva para el derecho natural son bien conocidas.

Toda ley positiva está condicionada por el grado de conocimiento del derecho natural. Una gran parte proviene de épocas en las que la ciencia estaba en ciernes, otras muchas han rechazado la ayuda de esta. De ahí la consecuencia inevitable de que el contenido de la ley positiva contenga tanto verdades como falsedades; otra consecuencia consiste en la lucha del derecho natural contra la ley positiva.

Pero incluso respecto al contenido verdadero, la forma y expresión de la ley positiva es a menudo inadecuada; de ahí las lagunas, contradicciones, puntos oscuros y dudas.

Como la ley positiva es rígida y el derecho es progresivo, incluso la verdad de ella se convierte en falsedad con el tiempo. La derogación de una ley por otra nueva nunca puede llevarse a cabo sin violencia, ya que carece del desenvolvimiento constante y por tanto suave del derecho natural.

La ley positiva es abstracta y su necesaria simplicidad borra la riqueza del caso concreto. De ahí las inciertas creaciones de la equidad y del arbitrio judicial.

En su determinación última, el derecho positivo es absoluta arbitrariedad. Si la mayoría de edad comienza a los veinticuatro o veinticinco años; si el plazo de prescripción es de treinta años o de treinta y un años, seis semanas y tres días; si la forma escrita de los contratos debe comenzar con cincuenta 
táleros; cuál deba ser la medida concreta de las penas: ¿quién sería capaz de deducir la respuesta de la necesidad del objeto?

La ley positiva se convierte entonces en un arma inerte y siempre disponible, tanto para la sabiduría del legislador como para la pasión del déspota.

Consideraciones similares están en la base del conocido manifiesto de Savigny sobre la carencia de vocación legal de nuestro tiempo. Se le acusó de ir demasiado lejos. $\mathrm{Y}$ al respecto, quiero decir que su problema no fue ir demasiado lejos, sino quedarse corto. No sólo el presente: ningún tiempo está llamado a la legislación en el sentido aquí visto. Fue una ingenua ilusión pensar que, con solo dejarle el tiempo suficiente, la ciencia alcanzaría y comprendería el presente. El derecho siempre va por delante de la ciencia. Ninguna legislación positiva, aun con mil años de previa preparación, evitará los males que acabamos de señalar. Por tanto, el mayor elogio que se puede decir de este gran hombre de ciencia es que, incluso cuando tenía en sus manos el poder de legislar, no hizo ley alguna.

$\mathrm{Si}$, como se ha demostrado, el derecho natural sufre gravemente por la ley positiva, más aún padece la ciencia. De sacerdotisa de la verdad, la ley positiva la convierte en sierva del azar, del error, de la pasión y de la ignorancia. En lugar de lo eterno y lo absoluto, lo accidental y defectuoso se convierte en su materia. Del éter del cielo, cae y se hunde en el fango de la tierra.

Lejos de mí afirmar que la ley positiva no contiene más que falsedad. Una gran parte es verdadera, quizás incluso sólo la menor parte sea falsa. Pero en la medida en que la ley positiva por su contenido y forma es la verdadera expresión de la ley natural, ya ha hecho y logrado lo que es asunto y afán de la ciencia, cuya meta es igualmente descubrir las verdaderas leyes del derecho. A este respecto, entonces, lo único que le queda a la ciencia es el trabajo de explicación, el esclarecimiento, el trabajo del maestro de escuela. No es de extrañar que la ciencia no quiera lidiar con eso. Uno se pregunta a menudo por qué los códigos de derecho suprimieron en todas partes la ciencia por largo tiempo, buscando diversas justificaciones para ello, se llegó a considerar esto una razón para censurar dichos códigos. Pero la verdad se encuentra en lo contrario. Cuanto más éxito tiene en su análisis el código, más se acerca a la verdad, mayor es su contenido de la ciencia misma, capturado en la forma más precisa; es decir, lo mismo que la ciencia puede dar. Por tanto, es natural que la ciencia sólo recupere espacio en lo relativo a la parte buena del código cuando, por el transcurso del tiempo, la evolución del derecho haya superado la ley positiva. 
Si la ciencia no tiene nada que decir de la parte verdadera de toda ley positiva, entonces sólo le queda lo falso, y en todos los tiempos se abalanzó sobre ello con afán y avidez.

¿Cuál es el contenido de todos esos comentarios, exégesis, monografías, cuestiones, meditaciones, tratados y casos? Sólo una pequeña parte tiene al derecho natural como su materia; más de nueve décimas partes tienen que ver con las lagunas, ambigüedades, contradicciones, con lo falso, obsoleto y arbitrario de las leyes positivas. La ignorancia, la negligencia y la pasión del legislador son su materia. Incluso el genio se convierte en instrumento de la sinrazón, ofreciendo para justificarla toda su pericia, todo su saber. Los abogados se han convertido en gusanos de la ley positiva que solo viven en la madera podrida. Alejándose de la sana, sólo anidan en la enferma. Al convertir lo accidental en su objeto, la ciencia misma se vuelve accidental: tres palabras rectificadoras del legislador y bibliotecas enteras se convierten en papel mojado [Drei berichtigende Worte des Gesetzgebers und ganze Bibliotheken werden zu Makulatur].

Un juicio tan severo requiere pruebas detalladas. Sirvámonos de algunos ejemplos.

¿En qué se basa el interés jurídico en el proceso judicial polaco? Solo en la pobre definición que de la alta traición da el Derecho Territorial. La secesión de provincias enteras equivale ciertamente a revocar la constitución en el derecho natural; pero como la ley positiva pasa por alto este caso, las autoridades se ven obligadas, con la ayuda de diccionarios, historia y constituciones de países extranjeros, a construir un edificio artificioso que la defensa, con esas mismas armas, destruye cada día. Tres palabras complementarias del legislador, como promete el nuevo anteproyecto, y todos esos trabajos, a pesar de su alto valor científico, perderán todo su interés.

Esas minuciosas e interesantes explicaciones que en los pleitos sobre la prensa han tenido lugar en los últimos años, acerca de si el permiso de impresión del censor de otro Estado federado ampara también al autor en el suyo propio, ¿̇en qué se basan? En la ambigua versión del § 7 de la Ley del Bundestag de 20 de septiembre de 1819. Sólo en la medida en que esas explicaciones se refieran a la naturaleza de la cosa, a la que mira el derecho natural, pueden tener un valor duradero; lo demás no es menos científico, pero nadie lo ha leído desde que apareció la Declaración de este año.

La cuestión de si hay dos o tres grados de culpa ha sido la manzana de la discordia entre los juristas durante siglos. Desde el punto de vista del derecho 
natural existía un amplio acuerdo. Este no conoce tales números y particiones en un objeto esencialmente compacto. Ya [Ludwig Julius Friedrich] Hoepfner admite que la práctica no se preocupa del grado de la culpa, sino de la existencia misma de esta. Pero para el derecho romano, bastaron unos pocos pasajes, que no están claramente definidos y que se han vuelto ambiguos al separarse de su contexto, para ocupar completamente a los eruditos.

Se pueden llenar bibliotecas enteras con las obras relativas a la preferencia de la hija heredera [Vorzug der Erbtochter oder Regredienterbin]. Hubiera bastado un párrafo algo más concreto en el liber feudorum, y toda esta erudición no habría visto la luz del día.

Para evitar la impresión de que mis ejemplos han sido seleccionados a propósito, he traído conmigo el último volumen de las decisiones del Tribunal Supremo [Geheimen Obertribunals]. No haré ninguna selección y empezaré por la primera resolución plenaria, examinando una tras otra. Los considerandos se distinguen por la erudición y el ingenio, y son al menos equivalentes a los de los volúmenes anteriores. Pero ¿̇cuál es el tema de tan excelentes discusiones científicas? ¿Es lo absoluto, lo verdadero, lo necesario? ¿Tienen esas obras científicas una duración inmortal, una utilidad ilimitada, como exige la ciencia?

La primera resolución plenaria trata la cuestión de si las formas para autentificar la rúbrica de las partes analfabetas son para el juez las mismas en los contratos que en los actos procesales. Esta pregunta da lugar a una discusión de nueve páginas sobre las leyes positivas que se refieren al asunto; y, sin embargo, toda la duda radica únicamente a una redacción inadecuada del apéndice del Ordenamiento Judicial General. Si las disposiciones de la Circular del 30 de diciembre de 1798 hubieran sido dispuestas correctamente, de forma que estuvieran referidas naturalmente a ambos tipos de negociaciones, sobraría esta resolución plenaria con sus discusiones. El objeto de la resolución es un defecto, y una pequeña rectificación de la ordenación del apéndice deja sin significado científico a la misma.

La siguiente resolución plenaria trata la cuestión de si el usufructuario está obligado, no sólo frente al propietario sino también frente al acreedor hipotecario, a pagar los intereses de las deudas sobre la cosa. Es el tema de una investigación de veinticuatro páginas, minuciosa y aguda.

Previamente este problema ya había sido investigado por seis académicos, entre ellos Bornemann y Koch. Para el derecho natural, la cuestión no plantea dudas; por su naturaleza, el derecho real no admite una obligación personal, 
como reconoce expresamente Bornemann. Las dudas surgen de la forma en que está redactado el § 70, título 21, parte I del Derecho Territorial General [Allgemeines Landrecht ${ }^{3}$ ], donde se establece: "el usufructuario debe pagar los intereses de las deudas que gravan la cosa”.

Si este párrafo se hubiese redactado con arreglo a la fórmula de nuestro más alto Tribunal, habrían sobrado todas aquellas agudas investigaciones, que desde luego perderán todo su valor en cuanto el legislador decida corregir sus errores.

La siguiente resolución plenaria estipula que no es necesario un consentimiento por escrito del marido para los préstamos a su mujer de más de cincuenta táleros. La torpe formulación de la ley conduce obviamente a la decisión opuesta, porque según el § 133, título 5, parte I del Derecho Territorial General, incluso las declaraciones unilaterales de voluntad referentes a objetos de valor superior a cincuenta táleros, cuando sus consecuencias se extienden al futuro, deben hacerse por escrito, sin que se haga excepción alguna con respecto al derecho patrimonial de la pareja casada. Sólo la equidad, el derecho natural, exige evidentemente la disposición contraria, como se indica en los considerandos de la resolución. Por lo tanto, para eliminar el error del derecho, esta vez no formal sino material, se requiere todo el ingenio, para encontrar un subterfugio que permita eludirlo y afirmar el derecho natural; y esa escapatoria se encuentra, ciertamente de una manera un tanto atrevida, en que el consentimiento no constituye una declaración de voluntad.

La siguiente resolución plenaria ofrece un contraste notable con esto. Uno casi debería creer que se trata de un juego del azar. Estipula que el consentimiento de la mujer sobre la venta por parte del hombre de los bienes comunes del matrimonio debe darse por escrito. Podría pensarse que se trata de la misma cuestión, que aquí se resuelve de manera afirmativa y anteriormente de manera negativa, y de hecho se necesita una exposición de dieciséis páginas basada en la historia del código y el derecho común para encontrar una diferencia. La verdadera razón para no usar las palabras del § 133, título 5, parte I del Derecho Territorial General ha sido simplemente salvar la coherencia de la interpretación del párrafo hecha en el caso anterior.

Como puede observarse, la solución fundada en la naturaleza de la cosa es sencilla en ambos casos: la erudición y el arte de interpretación empleados no se dirigen hacia el derecho natural y su determinación, sino hacia la elimina-

3 ALR - Allgemeines Landrecht für die Preussischen Staaten (Derecho territorial general para los Estados prusianos, 1794). 
ción de la violencia que la ley positiva ha infligido a este derecho a través de sus reglas abstractas.

La siguiente resolución plenaria vuelve a tener que ver únicamente con la mala redacción de la ley. Se discute una cuestión que ha preocupado a los tribunales, al ministerio público y a los intérpretes muchas veces: qué debe entenderse por los capitales asignados a los hijos en concepto de garantía especial, y sobre los cuales, a tenor del § 169, título 2, parte II del Derecho Territorial General, el padre no debe tener plena disposición. La razón de todas estas múltiples discusiones está aquí en que lo expresado en la ley como "capitales considerados como garantía" [zur Sicherheit verschriebene Kapitalien] es una categoría que no aparece en ningún otro lugar del código y tampoco se desarrolla aquí, además tampoco se compagina fácilmente con los principios del derecho hipotecario prusiano. De ahí las múltiples dudas y las sabias discusiones para subsanar su falta.

La siguiente resolución plenaria vuelve a reconciliar la ley positiva con el derecho natural y a mediar entre ellos. Es bien sabido que en la mayoría de las provincias del Estado prevalece la costumbre de que el campesino, al acercarse a la vejez, cede la hacienda a uno de sus hijos, quien está obligado a pagar ciertas cantidades del precio de la cesión a sus hermanos cuando se casan o inician su propia vida. Tal como el pueblo entiende esta institución, no hay duda de que los hermanos pueden reclamar judicialmente las sumas así percibidas, aunque no hayan sido incorporadas en el contrato, siempre y cuando el padre no se oponga.

Desafortunadamente, el Derecho Territorial pasó por alto esta institución, y por lo tanto solo contamos con las disposiciones generales del § 75, título 5, parte I del Derecho Territorial General, según las cuales un tercero sólo puede reclamar judicialmente los beneficios que se le asignan en contrato suscrito por otros, si los ha aceptado con asentimiento de estos, adhiriéndose al contrato. Sin embargo, la aplicación de esta disposición somete la institución a un rigor insoportable y por eso siempre se ha buscado un remedio para sustraerla del efecto destructivo del $\S 75$. Se intentaron ficciones, conversiones, sucesiones anticipadas y otros artificios por el estilo para flexibilizar la ley positiva. El Tribunal Supremo demuestra con fundamento que estos remedios no son aplicables al Derecho Territorial; pero, al objeto de salvar la ya histórica institución, ofrece a su vez una nueva salida. Sin embargo, no sé si se le puede llamar adecuada: se convierte al padre en apoderado de los hijos y se estima que ha aceptado en nombre de ellos. Dejando aparte que los 
mencionados contratos normalmente no aluden con ninguna palabra a esta construcción, se opone a esta teoría que, en contra de la naturaleza de la cosa, una y la misma persona sea la que ofrece y la que acepta, y que los derechos de los hermanos se incrementan más allá de lo que cabría esperar del derecho natural. Porque según esta opinión, el propio padre también pierde todo derecho sobre la suma asignada, lo que es contrario a la naturaleza de esta institución. La razón de todos estos múltiples intentos de la ciencia es la carencia del Código, y uno solo puede protestar al ver cómo el ingenio y la erudición se esfuerzan en vano por corregir este error.

Permítanme interrumpir aquí este recorrido, pues creo que he proporcionado suficientes pruebas de la tesis de que sólo el error, la deficiencia de todo tipo, es el objeto casi exclusivo del que la jurisprudencia se ocupa, o mejor dicho, se ve lamentablemente obligada a ocuparse; cometido tan repugnante que resulta sorprendente encontrar a tantos dispuestos a realizarlo. Puede que sea un cometido necesario, pero no digno de la ciencia.

iQué altura de miras encontramos, sin embargo, en las ciencias naturales! Su objeto es sólo lo natural, lo eterno, lo necesario. La más pequeña brizna de hierba lleva este sello; toda criatura es verdadera, coherente consigo misma y la arbitrariedad no puede falsear la ciencia.

Estas ciencias también tienen errores, leyes falsas, pero basta una mirada brillante del genio para hacer desaparecer los errores como la noche ante el sol. Sólo la jurisprudencia soporta la vergüenza de servir al error y honrar la ignorancia durante siglos, a pesar del aumento de su saber.

Sin embargo, los sufrimientos de nuestra ciencia no se agotan aquí. El esquematismo, la rígida forma de la ley positiva, penetra en la jurisprudencia. La ciencia debe despreciar la riqueza del caso concreto, aunque la reconozca. La ley positiva es como un sastre testarudo que solo tiene tres medidas para todos sus clientes. La ciencia es el alma bondadosa que observa dónde el traje no ajusta bien. Pero el respeto que tiene por su señor solo le permite abrir la costura aquí y allá e insertar un retal.

La arbitrariedad en las determinaciones finales de la ley positiva también se abre paso en la ciencia. Lo arbitrario de las delimitaciones de formas, plazos, instrucciones, son por su naturaleza una fuente inagotable de dudas, a pesar de la más cuidadosa redacción. La ciencia recibe la ingrata tarea de resolver estas dudas, erigiendo la arbitrariedad en sistema. Todos los comentarios donde se tratan tales formalidades son extensísimos. Las solemnidades de los testamentos en el derecho romano, la notificación a las mujeres en la 
fianza del Derecho Territorial, se han convertido en tesoros para la erudición. Una ley completamente nueva de 1845 sobre la forma de los actos notariales proporciona un ejemplo brillante. Ciertamente se ha tenido el mayor cuidado en la redacción de esta ley y, sin embargo, qué cantidad de dudas ha despertado su aplicación en apenas dos años. Al mirar más de cerca la naturaleza de estas dudas, la ciencia no puede sino avergonzase.

¿El documento notarial tiene que escribirse realmente o se pueden utilizar y completar formularios litografiados?

¿Es inadmisible como testigo sólo el escribiente del notario actuante o lo son también los de cualquier notario del reino?

¿Tiene que atestiguar la firma de las partes analfabetas el notario actuante $\mathrm{u}$ otro notario?

¿El notario sólo tiene que firmar con su nombre, apellido y el lugar, o también su título?

Y cosas por el estilo, todo ello a riesgo de que el acto sea inválido. Me remito a las instrucciones ministeriales de este año.

Estas son las tareas importantes de la ciencia. Resolver tales dudas es su trabajo ahora. iCuán altas parecen todas las demás ciencias a este respecto! Junto a la grandísima posibilidad de esquematizar su contenido, coexiste el más rico desarrollo y multiplicidad de lo individual; junto a la máxima de su objeto, no hay rastro de arbitrariedad, sólo absoluta necesidad.

Hasta el momento la investigación se ha fundado en una comparación del objeto de la jurisprudencia con el de las otras ciencias. Ahora, la persecución de mi empresa me conduce a otro problema. Si hasta aquí la ciencia del derecho ha resultado obstaculizada por su sujeto, el derecho natural; ahora mostraré cómo la misma ciencia, al adaptar su forma al objeto estudiado, ejerce una fuerza destructiva sobre el derecho, como si quisiera castigar la resistencia obstinada del objeto con la destrucción de su ser.

El derecho no puede existir sin estos dos elementos: el conocimiento y el sentimiento. Un pueblo debe saber lo que exige la ley en cada caso particular, y debe dedicarse con amor a su derecho. Sin estos elementos, el derecho seguirá siendo una gran obra de arte, pero muerta, iya no será derecho! Al acercarse la ciencia al derecho como su propio objeto, la destrucción de estos elementos es inevitable. El pueblo pierde la noción del propio derecho y el apego hacia él. El derecho se convierte en patrimonio exclusivo de una clase especial. Esto resulta de la naturaleza de la cosa, y así lo enseña la historia. Por tanto, la ciencia entra en contradicción consigo misma; al querer 
entender su objeto, lo aniquila. Las consecuencias de esta contradicción son extraordinarias.

La ciencia, privada de su terreno natural, se extravía con demasiada facilidad en el camino de la sofisticación, de elucubraciones estériles. El resultado es rico en sutilezas, se dan excesos de todo tipo, tan abundantes en la literatura jurídica.

La vacilación de la legislación es otra consecuencia. De hecho, el legislador se ha dedicado incluso a experimentar. La legislación procesal prusiana de 1833 proporciona un buen ejemplo, sobre todo en lo referido a los recursos [Rechtsmittel].

No obstante, los mayores inconvenientes surgen en la aplicación del derecho al caso concreto. Incluso los actos de jurisdicción voluntaria están desfigurados por toda clase de formularios y artificios. Pero la cosa es todavía más grave en lo referido a los procesos. No me refiero a los procesos ejecutivos, donde sólo hay que vencer la indolencia y la mala voluntad del deudor: no constituyen auténticas controversias jurídicas y no requieren jurisprudencia ni jueces. Mas los verdaderos procesos, donde existen verdaderas controversias jurídicas, quedan reducidos por el efecto destructivo de la ciencia para la nación a una mera operación, a una simple especulación, como cualquier otra, sin que quede rastro de la auténtica realización del derecho.

Ninguna de las partes sabe quién tiene la razón. La voz de la conciencia calla. Se consulta a los abogados. Sólo consideraciones extrínsecas, como la probabilidad de éxito, las costas, la duración del proceso, determinan la decisión. Si uno gana, bueno, entonces la acción ha tenido éxito. Si uno pierde, el hombre inteligente se consuela como el comerciante que ha perdido su rico cargamento en la tormenta; como el corredor de bolsa, cuyo cálculo ha sido frustrado por los acontecimientos políticos. Allí como aquí, no hay rastro de justicia, ningún sentimiento de indignación por la injusticia sufrida, ni orgullosa satisfacción por la victoria del derecho.

El curso externo del proceso está diseñado para respaldar este punto de vista. Incluso el juez y el erudito ignoran lo que procede en un caso dado. Hay que consultar primero voluminosos códigos y comentarios polvorientos; se debe hacer un cálculo artificial para encontrar lo que debe estar escrito claramente en el corazón de todos. En primera instancia se prueba con agudeza y erudición, de manera artificial, la verdad de una tesis, cuya falsedad se demuestra en la segunda instancia con igual agudeza e idéntica erudición. iY suerte si en la tercera instancia no se vuelve a invertir la verdad! 
¿Cómo puede la nación reconocer en estos cálculos artificiosos, deducciones eruditas, sentencias fluctuantes, el derecho que ha nacido y crecido con ella; el derecho cuyas claras expresiones deben estar escritas en cada corazón como algo sagrado e incorruptible? Se antoja imposible. La administración de justicia se ha convertido gracias a la ciencia en un juego de azar. Y por otra parte, las bajas pasiones libran en ella una pequeña guerra, ya que la paz impide otra más grande.

El lenguaje del hombre común tiene expresiones apropiadas para este estado de cosas. Si se le pregunta a un granjero cómo va su pleito, la respuesta es: todavía está en el aire. Una excelente expresión para describir la trayectoria sinuosa del asunto y la absoluta falta de sentido que tiene para las partes. Si el campesino pierde el pleito, no dirá que le faltaba la razón, sino más bien: me la jugué y perdí. La pérdida del proceso es para él un acontecimiento equiparable a la devastación de su campo por granizo: una desgracia, pero no una injusticia.

Este es el triunfo de la ciencia jurídica: un derecho que el pueblo ya no conoce, que no le llena ya el corazón, que coloca en pie de igualdad con las fuerzas ciegas de la naturaleza.

Un mal así es demasiado grande para dejar de reaccionar tan pronto como las naciones se vuelven más conscientes. Huellas de ello aparecen en todas las épocas.

Mencionemos a Justiniano y la prohibición de comentar su compilación. Por mucho que los eruditos lo ridiculizaran por esta razón, esta prohibición se basa en el muy respetable deseo de preservar el derecho del pueblo, protegiéndolo del poder destructivo de la erudición. Después de casi trece siglos, encontramos la misma prohibición en la patente de publicación del Derecho Territorial General, § 18 y en la introducción, § 47.

El intento de Federico el Grande de abolir los abogados tiene la misma base. La empresa estaba condenada al fracaso porque no llegaba al fondo: no han de suprimirse únicamente los abogados, sino también los jueces de carrera.

El mismo espíritu, hostil a la jurisprudencia, informa la obra legislativa del monarca, su Ordenamiento Judicial General. Su principio es el libre arbitrio de un juez honesto que se atenga a la equidad, y no la regla de la ciencia, basada en las más finas abstracciones y cálculos.

De esta contradicción interna entre el fin y el resultado de la jurisprudencia surgió esa extraña recomendación y el fomento de los compromisos ar- 
bitrales. El pueblo y el gobierno son unánimes en esto, y también, ingenuamente, los abogados. Y, sin embargo, desde el punto de vista de la ciencia, toda transacción es una vergüenza para ella; el más claro testimonium paupertatis. ¿Qué se diría de un matemático que aconsejara a dos personas que intentan resolver sus cuentas hacer una transacción porque el cálculo resulta demasiado tedioso e incierto? Otro símil: un hombre rico contrata un cochero, le da dinero y le dice que compre un carruaje cómodo, un arnés resistente y caballos fuertes. Hecho lo cual, el rico le ordena al cochero que se prepare para salir. En vez de hacerlo, el cochero alega que ir en carruaje es peligroso, engorroso e inseguro; que le irá mejor si camina. ¿No echará el amo de la casa a un cochero así? ¿Qué debe hacer la nación con los abogados que aconsejan hacer transacciones?

Esa pasión por los árbitros, la insistencia de todas las provincias por fortalecer y expandir la esfera de actividad de los mismos, ¿qué otra cosa es sino el oscuro presentimiento de ese mal y el afán por quitar la justicia de las manos de los jueces de carrera y devolverla a la nación? En una palabra: restablecer el derecho en su derecho. Esta es la única manera de explicar la contradicción de que en medicina los charlatanes son castigados y en jurisprudencia son privilegiados.

Por los mismos motivos se aboga a favor de tribunales mercantiles sin vocales de carrera, tribunales de fábrica, jueces de paz, etc. Así, los tribunales patrimoniales ${ }^{4}$ sólo pueden defenderse de los ataques de la ciencia por este motivo. Un juez patrimonial que lleve ejerciendo su cargo algún tiempo en un pueblo o en una pequeña ciudad muy pronto se encuentra en ese estado feliz, tan deseado por los vecinos, en el que ha olvidado todo lo aprendido y la fuente principal de sus decisiones se encuentra sólo en su corazón, en sus sentimientos jurídicos, idénticos a los de sus convecinos. Lo que el campesino y el burgués temen es que el juez sea un joven licenciado que emplea todo el fárrago de su erudición y conocimiento jurídico para resolver agudamente los diversos casos.

La necesidad de tribunales con jurado tiene la misma base. La ciencia no quiere admitir esto bajo ningún precio. Emplea todo el ingenio para marginar la ventaja del jurado, pero la mente sencilla de la gente de la que emana ese deseo, no conoce estas sutilezas. A través del jurado quiere eliminar, inconscientemente, la ciencia jurídica.

4 Los tribunales patrimoniales fueron establecidos por los señores territoriales y, por ello, eran independientes del sistema judicial nacional. 
Entonces todos estos fenómenos tienen la misma base. La nación está cansada de juristas científicos. Hay una sospecha, una oscura intuición de esa contradicción entre derecho y ciencia: tan sólo falta su clara comprensión por parte del pueblo. Uno aún no se atreve a formular estos pensamientos con claridad, de ahí la justificación de esos fenómenos por motivos externos e incorrectos. Pero tan pronto como se obtenga un conocimiento claro, será difícil detenerse en estos remedios aislados e incompletos, y el gobierno, al que los juristas también molestan, con mucho gusto le echará una mano. La administración de justicia será devuelta al pueblo no solo por la cuestión de hecho, sino también por la cuestión de derecho, no sólo en materia penal, sino también en materia civil. Otra consecuencia positiva será la reducción de las leyes positivas: estas se limitarán a formular los principios directivos y dejarán la aplicación de estos en sus ramificaciones sutiles al sano juicio del pueblo.

$\mathrm{Y}$, en verdad, no veo yo que esto resulte una desgracia. Los pleitos no durarán tantos días como lo hacen ahora durante meses y años; las costas ya no disuadirán a nadie para perseguir la justicia que le corresponde; las sentencias quizás estarán menos de acuerdo con las sutiles disposiciones de la ley positiva artificialmente construida, con los resultados aprendidos de la ciencia, pero en cambio estarán de acuerdo con la ley que vive en el pueblo. En la medida en que este haga valer su voz, entonces se realizará el derecho de una manera pura y sin distorsiones; y allí donde calle, donde el caso es demasiado complicado, al final habrá una solución rápida y equitativa, lo que constituye el principal objetivo. En estas conclusiones menores no cabe hablar de verdad o de derecho natural. Pero en ningún caso la jurisprudencia puede quejarse si en tales supuestos no se pregunta por su verdad, pues se trata de una verdad que después de una larga espera se construye artificialmente sobre la base de cien libros, pero que ni siquiera puede sobrevivir a la segunda instancia en el mismo asunto.

Una administración de justicia como la expuesta, no es un sueño producto de la imaginación. Naciones enteras han vivido y crecido sin juristas eruditos, sin esas estructuras artificiales de las leyes positivas, especialmente en el derecho privado. Los griegos, incluso en sus tiempos más brillantes, no tenían tales cosas. Los jueces populares fallaban con arreglo al derecho que la costumbre había consagrado, que oían en su corazón. Sus grandes pensadores, Platón y Aristóteles, no conciben que la interpretación de las leyes positivas, esa mezquina disputa sobre sus dudas y oscuridades, pueda reclamar la dig- 
nidad de la ciencia. Tales cosas son tan insignificantes para ellos que no se detienen en ellas en ninguna parte de sus escritos, por lo demás tan prácticos. Incluso con los romanos, hasta bien entrado el periodo imperial, cuando ciertamente hubo un gran comercio y tráfico, donde no se puede negar la complejidad de la situación, la administración de justicia estaba en manos de jueces ignorantes; el pretor era por regla general un funcionario sin ninguna educación académica. Su obra, el edicto, cuyas disposiciones sólo se toman del derecho natural, lo atestigua, y los judices eran puramente hombres del pueblo que decidían la cuestión de hecho enteramente de acuerdo con su llano juicio, incluso en la cuestión de derecho es dudoso que se atuvieran a la formula praescripta del pretor con la minuciosidad que refieren nuestros manuales.

En mis cargos oficiales he visitado e inspeccionado más de doscientos tribunales. He presenciado varios casos en los que la pereza y la imprudencia del juez habían alcanzado tal grado que la administración de justicia se paralizó por completo. Las demandas no se tramitaban, no se legalizaban los contratos, no existía el registro hipotecario; en lugar de legajos, solo había hojas sueltas esparcidas por todas partes. A pesar de que dicha situación se había prolongado durante años, la gente de tales distritos no era más pobre, el lugar no estaba más desolado que cualquier otro sitio. La gente había acudido a las transacciones, acudiendo al maestro de escuela y al alcalde en lugar del juez.

En Inglaterra, tal estado de cosas no es la excepción sino la regla, debido al gran número de sus leyes parlamentarias. La administración de justicia allí es un lujo, un artículo para los ricos. El importante órgano del juez de paz no es un jurista profesional y, sin embargo, esto no ha impedido que el país se convierta en el más grande y poderoso del mundo.

Hemos puesto de relieve los obstáculos inmanentes al objeto de la jurisprudencia: la contradicción entre el comienzo y el resultado de la elaboración científica del derecho. Queda todavía una pregunta por resolver: ¿qué tipo de herramientas ha inventado la jurisprudencia? ¿Qué tipo de instituciones ha creado para hacer más asequible su objeto a la humanidad, para mitigar el peso y el dolor del proceso descrito?

Todas las demás ciencias han prestado brillantes servicios a la humanidad, en esto sus creaciones rozan lo maravilloso. Las ciencias naturales y las matemáticas son las primeras. Han llevado al hombre, a través de las olas del océano, a las profundidades de la tierra; canales, ferrocarriles y telégrafos casi han cancelado las distancias. Los microscopios han llevado a las maravillas de la naturaleza más pequeña, y los telescopios han abierto los espacios del 
cielo, y el rayo de luz se ha convertido en un fiel dibujante de rasgos amados. Las otras ciencias tampoco se han quedado atrás. La psicología ha apoyado enormemente el arte de la educación y mejorado el método de enseñanza, mientras la mnemotecnia y la frenología ofrecen sus servicios.

Por el contrario, ¿cuáles son los servicios de la jurisprudencia? Miro ansiosamente en todas direcciones y lo que encuentro son formularios de negocios jurídicos y actos procesales. Una multitud de advertencias, instrucciones, formularios y cláusulas, supuestamente para suplir la ligereza y proteger contra los pleitos; finalmente, todo el aparato del proceso común, lleno de solidez y erudición, en una palabra, todo menos la manera de conseguir uno su derecho en el término de una vida. Esto es prácticamente todo lo que debemos a los científicos del derecho a este respecto. En cambio, buscaremos en vano una ayuda, una orientación de la ciencia donde realmente se requiere, es decir, en el perfeccionamiento general del derecho.

Cada época tiene sus cuestiones jurídicas que conmueven profundamente a la nación: a veces afectan a la familia, a veces a la relación entre la Iglesia y el Estado, a veces a la constitución de este último, a veces a los privilegios de clases individuales y a veces a la relación internacional de los pueblos. La lucha gira en torno a estas cuestiones, las facciones se unen; indican los lugares donde se extinguió la vieja regulación, donde el derecho presiona por una nueva forma. La gran masa de la nación siempre es prudente al comienzo de este proceso. Ante la confusión, recurre a la ciencia interrogándola en busca de una solución para sus dudas, en busca de orientación en el oscuro curso del desarrollo. Pero la ciencia siempre se ha mostrado impotente para hacer esto; nunca ha entendido el presente. Los pueblos quedaron abandonados a sí mismos. No es de extrañar que cayeran en manos de facciones y, en lugar del camino recto del desarrollo constante, tuvieran que tomar los caminos equivocados de la pasión, los desvíos del error, antes de alcanzar su meta.

La historia nos enseña que esto ha sucedido en todos los pueblos. Los juristas romanos, inmersos en la cultura del derecho privado, eran obedientes servidores de la tiranía. Con la misma calma, con la misma minuciosidad comentaron tanto la constitución despótica de la época imperial como la ley de la república que respira libertad. La seguridad del tráfico en este gran imperio exigía con urgencia la protección de la buena fe y un derecho de prenda fácilmente reconocible pero flexible. En cambio, los juristas romanos mantuvieron rígidamente la estricta rei vindicatio y construyeron un derecho de prenda con privilegios tales que ellos mismos tuvieron que aconsejar a los tutores 
que enterraran el dinero en efectivo de sus pupilos en lugar de prestarlo con hipoteca. Los juristas romanos tampoco pudieron comprender el tremendo cambio que había traído consigo el cristianismo en el derecho privado. Justiniano, el legislador acientífico, es mucho más agudo que ellos. Él y, más tarde, los papas dieron espacio al nuevo espíritu en el derecho privado. Me limito a recordar aquí el valor de la bona fides en la prescripción y el possessorium summariissimum.

El caso alemán no refiere cosas mejores sobre sus juristas. Los príncipes y los pueblos tuvieron que arreglárselas ellos mismos con su natural entendimiento en todas las crisis, en todas las innovaciones. Los juristas no aconsejaron la lucha de los emperadores francos contra los poseedores de los grandes ducados para fortalecer el poder imperial. Cuando la Reforma había destruido la antigua constitución de la Iglesia, y se trataba de encontrar y dar forma a la nueva y verdadera relación jurídica entre los príncipes y la Iglesia protestante, entre el poder de la Iglesia y la comunidad, en ninguna parte encuentro una apariencia de jurisprudencia para explicar la verdadera situación, la institución más convincente: dejó que los príncipes y los reformadores buscaran a tientas y todavía hoy sufrimos por este fracaso de la ciencia.

El tráfico más animado de nuestro siglo y la creciente fragmentación de la tierra exigen urgentemente una simplificación del registro hipotecario. Lo que la legislación prusiana más reciente ha ofrecido, la conocida Reforma de Campos Convertibles [Formular für Wandelacker], no es suficiente. Sólo puede llevarse adelante en las antiguas provincias que poseen un gran número de funcionarios. Impone al juez transcripciones larguísimas y mecánicas, y el menor error supone un peligro para el público y el propio juez. La verdad es que hasta la fecha, la ciencia no ha sabido ofrecer nada que mejore lo que el simple sentido de los funcionarios ignorantes descubrió después de la extinción de los tribunales populares: los libros de comercio y consentimiento [Handels-und Consensbücher]. La modalidad francesa del registro hipotecario es similar y, aparte de las deficiencias materiales de la ley hipotecaria francesa, ha demostrado ser viable hasta el día de hoy y ha demostrado ser practicable con poco personal, aunque la división de la tierra en Francia ya ha alcanzado 125 millones de fincas.

No se puede objetar a estos ataques que tales cosas no pertenecen a la jurisprudencia, sino a la política y al arte de legislar. Es precisamente esto lo penoso de la jurisprudencia, que aísla la política de sí misma, que se declara incapaz de dominar o, al menos, guiar la materia y el discurrir de las nuevas 
formaciones; mientras que todas las demás ciencias consideran esta su parte esencial, su tarea suprema.

El tan propugnado perfeccionamiento del derecho por parte de los juristas, sobre el que ahora se puede leer en todos los compendios, sólo se refiere al juego de los ínfimos detalles. Los juristas no son capaces de sentar las bases para levantar la estructura misma de un edificio sólido. Pero cuando el edificio está terminado, cuando los pilares lo sostienen, entonces como los cuervos acuden a millares y anidan por todas partes; miden los límites y dimensiones por pulgadas y líneas; pintan y adornan el noble edificio, hasta el punto de que ni el príncipe ni el pueblo reconocen ya apenas su propia obra.

He llegado al final de mi misión. El resultado que estoy ofreciendo es devastador y angustioso. Por tanto, es natural concluir con unas palabras de consuelo.

Quienes compartan conmigo la convicción expresada, o lleguen a compartirla después de una atenta consideración del problema, hallarán el consuelo en el hecho de la necesidad de la cosa, en el entendimiento de que lo sustancial no está en una clase determinada sino en la nación en su totalidad.

Donde mis comentarios solo han arañado la superficie, donde tan sólo han sacudido el árbol aún intacto de convicciones y prejuicios, no hay necesidad de consuelo. El buen humor inquebrantable de semejantes personas basta para imponer la alegría de la persona a la seriedad del tema.

Impreso por W. Moeser y Kühn en Berlín. 



\section{PROGRAMA HISTORIA DEL DERECHO PUBLICACIONES \\ ISSN: 2255-5137}

1. Luis Grau, Origenes del constitucionalismo americano. Corpus documental bilingüe / Selected Documents Illustrative of the American Constitutionalism. Bilingual edition, 3 vols., Madrid 2009, 653+671+607 pp.

http://hdl.handle.net/10016/5669

2. Luis Grau, Nosotros el pueblo de los Estados Unidos. La Constitución de los Estados Unidos y sus enmiendas. 1787-1992. Edición bilingüe / We the People of the United States. The U.S. Constitution and its Amendments. 1787-1992. Bilingual edition, Madrid 2010, $338 \mathrm{pp}$.

http://hdl.handle.net/10016/8517

3. Carlos Petit, Fiesta y contrato. Negocios taurinos en protocolos sevillanos (1777-1847), Madrid 2011, 182 pp.

http://hdl.handle.net/10016/10145

4. Pablo Mijangos y González, El nuevo pasado jurídico mexicano. Una revisión de la historiografía jurídica mexicana durante los últimos 20 años, Madrid 2011, 110 pp. http://hdl.handle.net/10016/10488

5. Luis Grau, El constitucionalismo americano. Materiales para un curso de historia de las constituciones, Madrid 2011, xxii+282 pp.

http://hdl.handle.net/10016/11865

6. Víctor Tau Anzoátegui, El taller del jurista. Sobre la Colección Documental de Benito de la Mata Linares, oidor, regente y consejero de Indias, Madrid 2011, 175 pp.

http://hdl.handle.net/10016/12735

7. Ramon Llull, Arte de Derecho, estudio preliminar de Rafael Ramis Barceló, traducción y notas de Pedro Ramis Serra y Rafael Ramis Barceló, Madrid 2011, 178 pp.

http://hdl.handle.net/10016/12762

8. Consuelo Carrasco García, ¿Legado de deuda? A vueltas con la Pandectística, Madrid 2011, 158 pp.

http://hdl.handle.net/10016/12823

9. Pio Caroni, Escritos sobre la codificación, traducción de Adela Mora Cañada y Manuel Martínez Neira, Madrid 2012, xxvi + 374 pp.

http://hdl.handle.net/10016/13028

10. Esteban Conde Naranjo (ed.), Vidas por el Derecho, Madrid 2012, 569 pp.

http://hdl.handle.net/10016/13565

11. Pierangelo Schiera, El constitucionalismo como discurso político, Madrid 2012, 144 pp. http://hdl.handle.net/10016/13962 
12. Rafael Ramis Barceló, Derecho natural, historia y razones para actuar. La contribución de Alasdair MacIntyre al pensamiento jurídico, Madrid 2012, 480 pp.

http://hdl.handle.net/10016/13983

13. Paola Miceli, Derecho consuetudinario y memoria. Práctica jurídica y costumbre en Castilla y León (siglos XI-XIV), Madrid 2012, 298 pp.

http://hdl.handle.net/10016/14294

14. Ricardo Marcelo Fonseca, Introducción teórica a la historia del derecho, prefacio de Paolo Cappellini, Madrid 2012, 168 pp.

http://hdl.handle.net/10016/14913

15. Alessandra Giuliani, Derecho dominical y tanteo comunal en la Castilla moderna, Madrid 2012, 134 pp.

http://hdl.handle.net/10016/15436

16. Luis Grau, An American Constitutional History Course for Non-American Students, Madrid 2012, xx + 318 pp.

http://hdl.handle.net/10016/16023

17. Antonio Ruiz Ballón, Pedro Gómez de la Serna (1806-1871). Apuntes para una biografía jurídica, Madrid 2013, 353 pp.

http://hdl.handle.net/10016/16392

18. Tamara El Khoury, Constitución mixta y modernización en Líbano, prólogo de Maurizio Fioravanti, Madrid 2013, 377 pp.

http://hdl.handle.net/10016/16543

19. María Paz Alonso Romero/Carlos Garriga Acosta, El régimen jurídico de la abogacía en Castilla (siglos XIII-XVIII), Madrid 2013, 337 pp.

http://hdl.handle.net/10016/16884

20. Pio Caroni, Lecciones de historia de la codificación, traducción de Adela Mora Cañada y Manuel Martínez Neira, Madrid 2013, 213 pp.

http://hdl.handle.net/10016/17310

21. Julián Gómez de Maya, Culebras de cascabel. Restricciones penales de la libertad ambulatoria en el derecho codificado español, Madrid 2013, 821 pp.

http://hdl.handle.net/10016/17322

22. François Hotman, Antitriboniano, o discurso sobre el estudio de las leyes, estudio preliminar de Manuel Martínez Neira, traducción de Adela Mora Cañada, Madrid 2013, 211 pp. http://hdl.handle.net/10016/17855

23. Jesús Vallejo, Maneras y motivos en Historia del Derecho, Madrid 2014, 184 pp.

http://hdl.handle.net/10016/18090

24. María José María e Izquierdo, Los proyectos recopiladores castellanos del siglo XVI en los códices del Monasterio de El Escorial, Madrid 2014, 248 pp.

http://hdl.handle.net/10016/18295 
25. Regina Polo Martín, Centralización, descentralización y autonomía en la España constitucional. Su gestación y evolución conceptual entre 1808 y 1936, Madrid 2014, 393 pp. http://hdl.handle.net/10016/18340

26. Massimo Meccarelli/Paolo Palchetti/Carlo Sotis (eds.), Il lato oscuro dei Diritti umani: esigenze emancipatorie e logiche di dominio nella tutela giuridica dell'individuo, Madrid 2014, 390 pp.

http://hdl.handle.net/10016/18380

27. María López de Ramón, La construcción histórica de la libertad de prensa: Ley de policía de imprenta de 1883, Madrid 2014, 143 pp.

http://hdl.handle.net/10016/19296

28. José María Coma Fort, Codex Theodosianus: historia de un texto, Madrid 2014, $536 \mathrm{pp}$.

http://hdl.handle.net/10016/19297

29. Jorge Alberto Núñez, Fernando Cadalso y la reforma penitenciaria en España (18831939), Madrid 2014, 487 pp.

http://hdl.handle.net/10016/19662

30. Carlos Petit, Discurso sobre el discurso. Oralidad y escritura en la cultura jurídica de la España liberal, Madrid 2014, 185 pp.

http://hdl.handle.net/10016/19670

31. Jean-Étienne-Marie Portalis, Discurso preliminar sobre el proyecto de Código civil, Madrid 2014, 53 pp.

http://hdl.handle.net/10016/19797

32. Cesare Beccaria, Tratado de los delitos y de las penas, Madrid 2015, 87 pp.

http://hdl.handle.net/10016/20199

33. Massimo Meccarelli/Paolo Palchetti (eds.), Derecho en movimiento: personas, derechos y derecho en la dinámica global, Madrid 2015, 256 pp.

http://hdl.handle.net/10016/20251

34. Alessandro Somma, Introducción al derecho comparado, traducción de Esteban Conde Naranjo, Madrid 2015, 193 pp.

http://hdl.handle.net/10016/20259

35. A. F. J. Thibaut, Sobre la necesidad de un derecho civil general para Alemania, Madrid 2015, 42 pp.

http://hdl.handle.net/10016/21166

36. J.-J.-R. de Cambacérès, Discursos sobre el Código civil, Madrid 2015, 61 pp.

http://hdl.handle.net/10016/21254

37. Ramon Llull, Arte breve de la invención del derecho, estudio preliminar de Rafael Ramis Barceló, traducción de Pedro Ramis Serra y Rafael Ramis Barceló, Madrid 2015, 233 pp. http://hdl.handle.net/10016/21406 
38. F. C. von Savigny, De la vocación de nuestra época para la legislación y la ciencia del Derecho, Madrid 2015, 130 pp.

http://hdl.handle.net/10016/21520

39. Joaquín Marín y Mendoza, Historia del derecho natural y de gentes, Madrid 2015, 40 pp. http://hdl.handle.net/10016/22079

40. Rafael Ramis Barceló, Petrus Ramus y el Derecho. Los juristas ramistas del siglo XVI, Madrid 2016, $250 \mathrm{pp}$.

http://hdl.handle.net/10016/22197

41. Emanuele Conte, La fuerza del texto. Casuística y categorías del derecho medieval, edición de Marta Madero, Madrid 2016, 194 pp.

http://hdl.handle.net/10016/22261

42. Constituciones españolas: 1808-1978, edición de Javier Carlos Díaz Rico, Madrid 2016, $259 \mathrm{pp}$.

http://hdl.handle.net/10016/22905

43. Giacomo Demarchi, Provincia y Territorio en la Constituyente española de 1931. Las raíces europeas del Estado integral, Madrid 2016, 362 pp.

http://hdl.handle.net/10016/22906

44. Miguel Ángel Ladero Quesada/César Olivera Serrano (dirs.), Documentos sobre Enrique IV de Castilla y su tiempo, Madrid 2016, $\mathrm{xx}+1446$ pp.

http://hdl.handle.net/10016/23015

45. Gustavo César Machado Cabral/Francesco Di Chiara/Óscar Hernández Santiago/Belinda Rodríguez Arrocha, El derecho penal en la edad moderna: Nuevas aproximaciones a la doctrina y a la práctica judicial, Madrid 2016, 217 pp.

http://hdl.handle.net/10016/23021

46. Lope de Deza, Juicio de las leyes civiles, estudio preliminar de Víctor Tau Anzoátegui, edición de María José María e Izquierdo, Madrid 2016, 136 pp.

http://hdl.handle.net/10016/23228

47. Henrik Brenkman, Historia de las Pandectas, estudio preliminar, traducción y notas de Juan Lorenzo, Madrid 2016, 426 pp.

http://hdl.handle.net/10016/23317

48. Massimo Meccarelli (a cura di), Diversità e discorso giuridico. Temi per un dialogo interdisciplinare su diritti e giustizia in tempo di transizione, Madrid 2016, 287 pp. http://hdl.handle.net/10016/23792

49. Beatrice Pasciuta, El diablo en el Paraíso. Derecho, teología y literatura en el Processus Satane (s. XIV), Madrid 2017, 264 pp.

http://hdl.handle.net/10016/24439

50. Maximiliano Hernández Marcos, Tras la luz de la ley: legislación y justicia en Prusia a finales del siglo XVIII. Un modelo de Ilustración jurídica, Madrid 2017, 184 pp.

http://hdl.handle.net/10016/24488 
51. Eleonora Dell'Elicine/Paola Miceli/Alejandro Morin (comps.), Artificios pasados. Nociones del derecho medieval, Madrid 2017, 307 pp.

http://hdl.handle.net/10016/24514

52. Eva Elizabeth Martínez Chavéz, Redes en el exilio. Francisco Ayala y el Fondo de Cultura Económica, Madrid 2017, 145 pp.

http://hdl.handle.net/10016/24715

53. Pierre de Jean Olivi, Tratado de los contratos, estudio preliminar de Rafael Ramis Barceló, traducción de Pedro Ramis Serra y Rafael Ramis Barceló, Madrid 2017, 171 pp. http://hdl.handle.net/10016/25200

54. Daniel Panateri, El discurso del rey. El discurso jurídico alfonsí y sus implicaciones políticas, Madrid 2017, 284 pp.

http://hdl.handle.net/10016/25377

55. Joaquín Costa, El problema de la ignorancia del derecho y sus relaciones con el estatus individual, el referéndum y la costumbre, Madrid 2017, 85 pp.

http://hdl.handle.net/10016/25578

56. Massimo Meccarelli (ed.), Reading the Crisis: Legal, Philosophical and Literary Perspectives, Madrid 2017, $224 \mathrm{pp}$.

http://hdl.handle.net/10016/25705

57. Pablo Ramírez Jerez/Manuel Martínez Neira, La historia del derecho en la Real Academia de Ciencias Morales y Políticas. Los concursos de derecho consuetudinario, Madrid 2017, 322 pp.

http://hdl.handle.net/10016/25809

58. Thomas Duve (coord.), Actas del XIX Congreso del Instituto Internacional de Historia del Derecho Indiano, 2 vols., Madrid 2017, 1681 pp.

http://hdl.handle.net/10016/25729

59. Víctor Saucedo, Conspiracy. A Conceptual Genealogy (Thirteenth to Early Eighteenth Century), Madrid 2017, 350 pp.

http://hdl.handle.net/10016/26095

60. Aurora Miguel Alonso (dir.), Doctores en derecho por la Universidad Central. Catálogo de tesis doctorales 1847-1914, Madrid 2017, 571 pp.

http://hdl.handle.net/10016/26198

61. François Hotman, Francogallia, o la Galia francesa, estudio preliminar y traducción de Tamara El Khoury, Madrid 2017.

http://hdl.handle.net/10016/26321

62. Rafael Altamira, Spain. Sources and Development of Law, estudio preliminar y edición de Carlos Petit, Madrid 2018, lxxxvi + 126 pp.

http://hdl.handle.net/10016/26322 
63. Jesús Delgado Echeverría, Joaquín Costa, jurista y sociólogo. Derecho consuetudinario e ignorancia de la ley, Madrid 2018, 174 pp.

http://hdl.handle.net/10016/26335

64. Rubén Pérez Trujillano, Creación de constitución, destrucción de Estado: la defensa extraordinaria de la II República española (1931-1936), Madrid 2018, 367 pp.

http://hdl.handle.net/10016/27108

65. Eugenia Torijano Pérez, Los estudios jurídicos en la universidad salmantina del siglo XIX, Madrid 2018, 625 pp. + apéndices complementarios.

http://hdl.handle.net/10016/27392

66. Laura Beck Varela/María Julia Solla Sastre (coordinadoras), Estudios Luso-Hispanos de Historia del Derecho. Estudos Luso-Hispanos de História do Direito, Madrid 2018, 543 pp.

http://hdl.handle.net/10016/27751

67. Manuel Martínez Neira/Pablo Ramírez Jerez, Hinojosa en la Real Academia de Ciencias Morales y Políticas, Madrid 2018, 279 pp.

http://hdl.handle.net/10016/27810

68. Rudolf von Jhering, La lucha por el derecho, estudio preliminar y edición de Luis Lloredo Alix, Madrid 2018, 137 pp.

http://hdl.handle.net/10016/27845

69. Enrique Roldán Cañizares, Luis Jiménez de Asúa: Derecho penal, República, Exilio, Madrid 2019, 406 pp.

http://hdl.handle.net/10016/28236

70. José María Puyol Montero, Enseñar derecho en la República. La Facultad de Madrid (1931-1939), Madrid 2019, 486 pp.

http://hdl.handle.net/10016/28286

71. Pedro L. López Herraiz, Formar al hombre de Estado. Génesis y desarrollo de la École libre des sciences politiques (1871-1900), Madrid 2019, 333 pp.

http://hdl.handle.net/10016/28313

72. Emiliano J. Buis, El juego de la ley. La poética cómica del derecho en las obras tempranas de Aristófanes (427-414 a.C.), Madrid 2019, 442 pp.

http://hdl.handle.net/10016/28358

73. Virginia Amorosi/Valerio Massimo Minale (ed.), History of Law and Other Humanities: Views of the Legal World Across the Time, Madrid 2019, 588 pp.

http://hdl.handle.net/10016/28459

74. Carlos Petit, Un Código civil perfecto y bien calculado. El proyecto de 1821 en la historia de la codificación, Madrid 2019, 409 pp.

http://hdl.handle.net/10016/28678 
75. Eduardo de Hinojosa, El elemento germánico en el derecho español, Madrid 2019, 82 pp. http://hdl.handle.net/10016/28877

76. Carlos Petit (ed.), Derecho ex cathedra. 1847-1936. Diccionario de catedráticos, Madrid 2019, 491 pp.

http://hdl.handle.net/10016/28916

77. Manuel Ángel Bermejo Castrillo (ed.), La memoria del jurista español. Estudios, Madrid 2019, 416 pp.

http:/hdl.handle.net/10016/29108

78. Elisabetta Fiocchi Malaspina/Simona Tarozzi (ed.), Historical Perspectives on Property and Land Law. An Interdisciplinary Dialogue on Methods and Research Approaches, Madrid 2019, 236 pp.

http:/hdl.handle.net/10016/29290

79. Daniel J. García López, La máquina teo-antropo-legal. La persona en la teoría jurídica franquista, Madrid 2020, $121 \mathrm{pp}$.

http://hdl.handle.net/10016/29463

80. Concepción Arenal, Las colonias penales de la Australia y la pena de deportación, Madrid 2020, 99 pp.

http://hdl.handle.net/10016/29667

81. Cristina Morales Segura, Galeotes de mercurio. El caso de Mateo Alemán: la interacción entre el derecho y la literatura en el informe de la mina de mercurio de Almadén y El Guzmán de Alfarache, Madrid 2020, 276 pp.

http://hdl.handle.net/10016/29888

82. Eduardo de Hinojosa, La condición civil de la mujer en el derecho español antiguo y moderno, Madrid 2020, 50 pp.

http://hdl.handle.net/10016/30043

83. Eduardo de Hinojosa, Influencia que tuvieron en el derecho público de su patria y singularmente en el derecho penal los filósofos y teólogos españoles anteriores a nuestro siglo, Madrid 2020, $146 \mathrm{pp}$.

http://hdl.handle.net/10016/30052

84. Eva Elizabeth Martínez Chávez, España en el recuerdo, México en la esperanza. Juristas republicanos del exilio, Madrid 2020, $343 \mathrm{pp}$.

http://hdl.handle.net/10016/30520

85. Rafael de Ureña y Smenjaud, Una tradición jurídica española: La autoridad paterna como el poder conjunto y solidario del padre y de la madre, estudio preliminar y edición de Carlos Petit, Madrid 2020, 174 pp.

http://hdl.handle.net/10016/30550

86. Carlos Petit, Derecho por entregas. Estudios sobre prensa y revistas en la España liberal, Madrid 2020, 311 pp.

http://hdl.handle.net/10016/30841 
87. Massimo Meccarelli/Cristiano Paixão/Claudia Roesler (ed.), Innovation and Transition in Law: Experiences and Theoretical Settings, Madrid 2020, 352 pp.

http://hdl.handle.net/10016/31394

88. Fernando Martínez-Pérez, Posesión, dominio y Registro. Constitución de la propiedad contemporánea en España (1861-1944), Madrid 2020, 286 pp.

http://hdl.handle.net/10016/31430

89. Fernando Liendo Tagle, Prensa jurídica española. Avance de un repertorio (1834-1936), Madrid 2020, 235 pp.

http://hdl.handle.net/10016/31583

90. Rafael Ramis Barceló, El nacimiento de la Filosofía del derecho. De la Philosophia iuris a la Rechtsphilosophie, Madrid 2021, 248 pp.

http://hdl.handle.net/10016/31704

91. Eugenia Torijano Pérez, Ser (de nuevo) doctor por Salamanca. Las tesis doctorales de la Facultad de Derecho en el Sexenio Revolucionario (1868-1874), Madrid 2021, 441 pp. http://hdl.handle.net/10016/31694

92. Víctor Saucedo, The Poulterers' Case (1611): A Landmark in the History of Criminal Conspiracy, Madrid 2021, 302 pp.

http://hdl.handle.net/10016/31790

93. Albert Venn Dicey, ¿Puede enseñarse el derecho inglés en las universidades?, estudio preliminar y traducción de Javier Carlos Díaz Rico, Madrid 2021, 134 pp.

http://hdl.handle.net/10016/31912

94. Cristina Nogueira da Silva/Margarida Seixas (coordenadoras), Estudos Luso-Hispanos de História do Direito. Estudios Luso-Hispanos de Historia del Derecho, vol. II, Madrid 2021, 648 pp.

http://hdl.handle.net/10016/32002

95. Giacomo Demarchi, Francesco Di Chiara, Elisabetta Fiocchi Malaspina, Belinda Rodríguez Arrocha (eds.), Las fronteras de la Ilustración. Itinerarios entre historia y derecho, Madrid 2021, 313 pp.

http://hdl.handle.net/10016/32201

96. Manuel Ángel Bermejo Castrillo (ed.), Temporalidades inter/disciplinares (Derecho, Filosofía, Política), Madrid 2021, 246 pp.

http://hdl.handle.net/10016/32263

97. Julius Hermann von Kirchmann, La falta de valor de la jurisprudencia como ciencia, Madrid 2021, 43 pp.

http://hdl.handle.net/10016/32336 